NBSIR 85-3197

\title{
Molecular and Microstructural Factors Affecting Mechanical Properties of Polymeric Cover Plate Materials
}

Elizabeth J. Clark

U.S. DEPARTMENT OF COMMERCE

National Bureau of Standards

Center for Building Technology

Gaithersburg, MD 20899

July 1985

Prepared for:

U.S. Department of Energy

Office of Solar Heat Technologies

$A B C \longrightarrow$ ating and Cooling Division

100

on, DC 20585

.056

$85-3197$ 

MOLECULAR AND MICROSTRUCTURAL FACTORS AFFECTING MECHANICAL PROPERTIES OF POLYMERIC COVER PLATE MATERIALS

Elizabeth J. Clark

U.S. DEPARTMENT OF COMMERCE

National Bureau of Standards

Center for Building Technology

Gaithersburg, MD 20899

July 1985

Prepared for:

U.S. Department of Energy

Office of Solar Heat Technologies

Washington, DC 20585

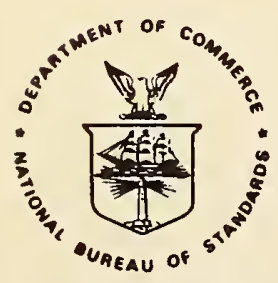

U.S. DEPARTMENT OF COMMERCE, Malcolm Baldrige, Secretary NATIONAL BUREAU OF STANDARDS, Ernest Ambler, Director 

1. Introduction. . . . . . . . . . . . . . . . . . 2

2. Background. . . . . . . . . . . . . . . . . . . . 3

3. Aspects of Polymer Physics and Chemistry. . . . . . . . . . . 4

3.1 Polymer Molecules. . . . . . . . . . . . . . 5

3.2 Bonding. . . . . . . . . . . . . . . . . 7

3.3 Solidification . . . . . . . . . . . . . . 7

3.4 Glass Transition . . . . . . . . . . . . . . . 10

4. Polymeric Cover Plate Materials . . . . . . . . . . . . . 12

5. Deformation and Mechanical Properties of Polymers . . . . . 16

5.1 Polymer Deformation and Fracture . . . . . . . . . . . 16

5.2 Mechanical Properties. . . . . . . . . . . . . . 23

6. Effect of Microstructural and Molecular Factors on Mechanical

Propert1es. . . . . . . . . . . . . . . . . 27

6.1 Molecular Welght . . . . . . . . . . . . 28

6.1.1 General .................. 28

6.1.2 Effect of Molecular Weight on Mechanical Properties . . 30

6.2 Crystallinity. . . . . . . . . . . . . 35

6.3 Crosslinking and Branching . . . . . . . . . . . 40

6.4 Copolymerization . . . . . . . . . . . . . 41

6.5 Plasticizers................... 41

6.6 Orlentation. . . . . . . . . . . . . . 42

6.7 Residual Stresses. . . . . . . . . . . . . 45

7. Degradation of Polymeric Cover Plates . . . . . . . . . 46

8. Discussion. . . . . . . . . . . . . . . 52

8.1 General. . . . . . . . . . . . . . . . 52

8.2 Polymer Microstructure . . . . . . . . . . . . . 52

8.3 Methods to Study Polymer Degradation and Deformation . . . 55

9. Summary . . . . . . . . . . . . . . . . . . 57

10. References. . . . . . . . . . . . . . 58 

This paper reviews the dependence of mechanical properties of polymers on various microstructural factors. The microstructural and molecular factors considered are: molecular weight, crystallinity, crosslinking, branching, copolymerization, plasticization, orientation, and residual stresses. The types of mechanical properties considered are: direct loading, fatigue, creep, wear and abrasion, and environmental stress cracking. The effects of polymer deformation and fraction at the molecular level are discussed. Cracking, crazing, and shear yielding are described. Polymeric cover plate materials are discussed and their degradation reviewed. Methods to measure microlevel changes in polymers are identified. 


\section{Introduction}

In solar collectors the cover plate simultaneously serves as a window for the sun and a structural component of the collector, thus placing prime importance on the optical and mechanical properties of the material. Polymers have long been used in applications requiring transparency, strength, and durability, for example, as windows, in greenhouses, and as jet plane canopies, so it is natural to consider them in collector glazing applications. Polymeric cover plate materials may play an important role in the future development of solar energy collectors if they can be shown to have adequately long service life. Use as solar collector cover plates imposes more severe demands on polymeric materials than most past large-scale uses because degradation may occur when polymers are used as collector glazings. Possible advantages of polymeric, rather than inorganic glass cover plates are: higher transmittance, better impact resistance (from some materials), lower cost, easier processing, lighter weight, and greater design flexibility. On the other hand, polymers are not as inert to their environment as the inorganic glasses they might replace.

The most significant difference between solar collector cover plates and other polymer applications requiring transparency, strength, and durability, is that cover plates are exposed simultaneously to elevated temperatures and natural outdoor weather. Optical and mechanical properties of polymers can be reduced by exposure to elevated temperatures or to outdoor weathering, and simultaneous exposure to both can lead to loss of solar transmittance and embrittlement of the polymer. Service life prediction of polymeric cover materials is difficult because knowledge of the relationships between polymer use, composition, morphology, and long term behavior are not well enough developed. As 
knowledge in polymer structure-property relationships is gained, and as correlations are established between weather factors and polymer degradation, service life prediction will improve. Past research on cover plate materials has emphasized transmittance changes as a measure of polymer degradation. This paper reviews the dependence of polymer mechanical properties on their composition and microstructure and shows the relationship between cover plate polymer degradation and microstructural changes.

\section{Background}

Mechanical properties are associated with resistance of a material to deformation under load. The mechanical properties of polymers are complex due to their viscoelastic nature which is demonstrated by a strong dependence of the mechanical properties on time and temperature [1]. This is a critical consideration for cover plate materials which encounter extended use at temperatures above ambient. Failure, in the sense of mechanical properties, occurs when the material breaks, tears, cracks, flows, or crazes.

The mechanical properties of polymers are dependent on many factors including microstructure, chemical composition, residual stresses, flaws, processing methods and history. Mechanical properties are properties of the bulk material, but they reflect phenomena occurring at the microscopic scale down to the molecular level. Polymer degradation begins on a molecular level with alteration of the polymer molecules and generally is accompanied or followed by changes in morphological properties (e.g., crystallinity or orientation) at the microscopic level. As degradation continues, the molecular and microscopic changes manifest themselves as macroscopic changes, e.g., changes in strength, elongation, and hardness. Measures of the microscopic level changes which occur earlier in the 
degradative process than macroscopic types, may be 1mportant as early degradation indicators. For service 11 fe prediction, it is desirable to have diagnostic tools able to detect and measure early changes which are clearly precursors in degradation processes. Since mechanical properties are so dependent on structural properties, monitoring microstructural changes should give an indication of mechanical property deterioration. Understanding the relationships between structure and properties of polymers has received increased emphasis in recent years but is not as well-developed as for metals and ceramics. There remains a major technical challenge to develop a basic understanding of the relationships between structure and end use performance and the scientific and technological framework needed for improving the durability of polymeric materials. As insight develops into the influence of microstructure on mechanical properties, it permits better choice of materials, improved processing, and an improved ability to predict if a material will meet the requirements of the application. It has been recognized that additional polymer research is needed to determine accurately the service life of commercial polymers used as glazing materials and to develop new polymers with long term durability under the exposure conditions of solar collectors $[2,3]$.

\section{Aspects of Polymer Physics and Chemistry}

To understand the mechanical properties of polymers, it is necessary to appreciate the nature of polymers. The two important considerations are the types of molecules and bonds which in turn influence the molecular morphology of polymers. These factors, along with the chemical composition control the solidification, flexibility, strength, and stability of polymers. 


\subsection{Polymer Molecules}

Polymer molecules consist of very long chains of covalently bonded atoms containing multiple sequences of a chemical structure, this repeating unit being unique for each polymer. Polymer properties are dependent on chemical composition and physical arrangement of the long molecular chains in space. The simplest polymer chain, polyethylene, is made up primarily of covalently bonded carbon atoms where the side structure on these carbon atoms is a hydrogen atom,

$$
\text { (i.e. } \begin{gathered}
\mathrm{H} \\
-\mathrm{C}-C \\
\mathrm{H} \\
\mathrm{H}
\end{gathered}
$$

Polymers vary by having other atoms or molecules substitute for $\mathrm{C}$ in the main chain backbone or $H$ as the side attachment. The flexibility of polymer chains depends on the atoms in the chain backbone, the size of the side groups, bond angles, the ease of rotation about the bonds, and bond energies. Bulky side groups make rotation and packing more difficult and may reduce structural regularity and interchain bonding. Ring structures in the main chain increase rigidity. Oxygen in the main chain provides greater ease of rotation and increases flexibility [4]. The flexibility of the bulk polymer is a direct result of the flexibility of the polymer chain on a microscopic level.

The structural repeat unit of several common cover plate polymers is shown in table 1. Poly(vinyl fluoride) (PVF) and poly(vinylidene fluoride) (PVDF) have the most simple repeat unit with two $C$ atoms in the backbone and $\mathrm{F}$ substituted for some of the side $\mathrm{H}$ atoms. Fluorinated ethylene propylene (FEP) is a random copolymer consisting of $80-90$ mol\% of the $-\mathrm{C}_{2}-\mathrm{F}_{4}$-units and $10-20 \mathrm{~mol} \%$ of the $-\mathrm{CF}_{2}-\mathrm{CF}-\mathrm{CF}_{3}$-units. Poly(methyl methacrylate) (PMMA) has two $C$ atoms in the main chain but bulky side 


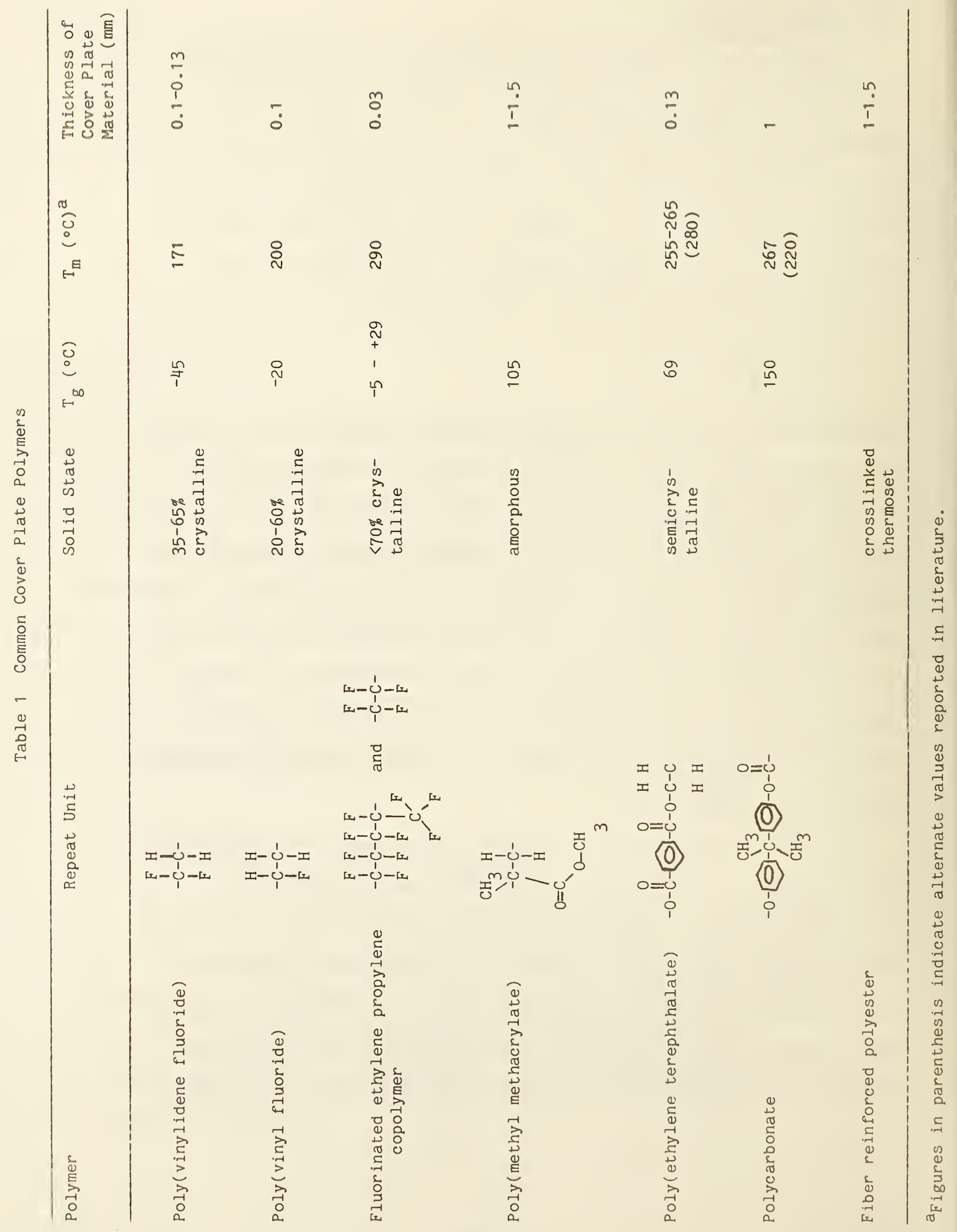


groups. The repeat units of polycarbonate (PC) and poly(ethylene

terephthalate) (PET) are large and contain a number of atoms in the main chain including both benzene rings and oxygen atoms.

\subsection{Bonding}

The strength and mechanical properties of polymers are influenced by the bonding between the molecules and the three-dimensional nature of the bulk material. Several types of bonding exist within polymers: chemical bonds between atoms within an individual polymer chain; secondary bonding (1ntermolecular forces) between adjacent molecules (e.8., London dispersion forces, induced polar-dipolar forces, and dipolar forces including hydrogen bonding); and physical entanglements of the long chains with adjacent chains [1].

\subsection{Solidification}

Most polymeric materials used as cover plates are fabricated by casting or extrusion of the molten material. The microstructure obtained on solidification is dependent on the polymer composition, rate of cooling, and stresses or orientation resulting from processing. The solidification of a linear polymer from the liquid gives either an amorphous solid or a partly crystalline one. In amorphous polymers the polymer chains are disordered. Semicrystalline polymers contain regions having both crystalline and amorphous materlal.

The crystallization behavior of polymers is unusual and results in a complex morphology due to the chain-like structure of the polymer molecules. Polymers crystallize by their constituent chains folding back and packing parallel to one another into thin platelets, as shown in figure 1. As a crystal grows, the platelet thickness remains fixed while 


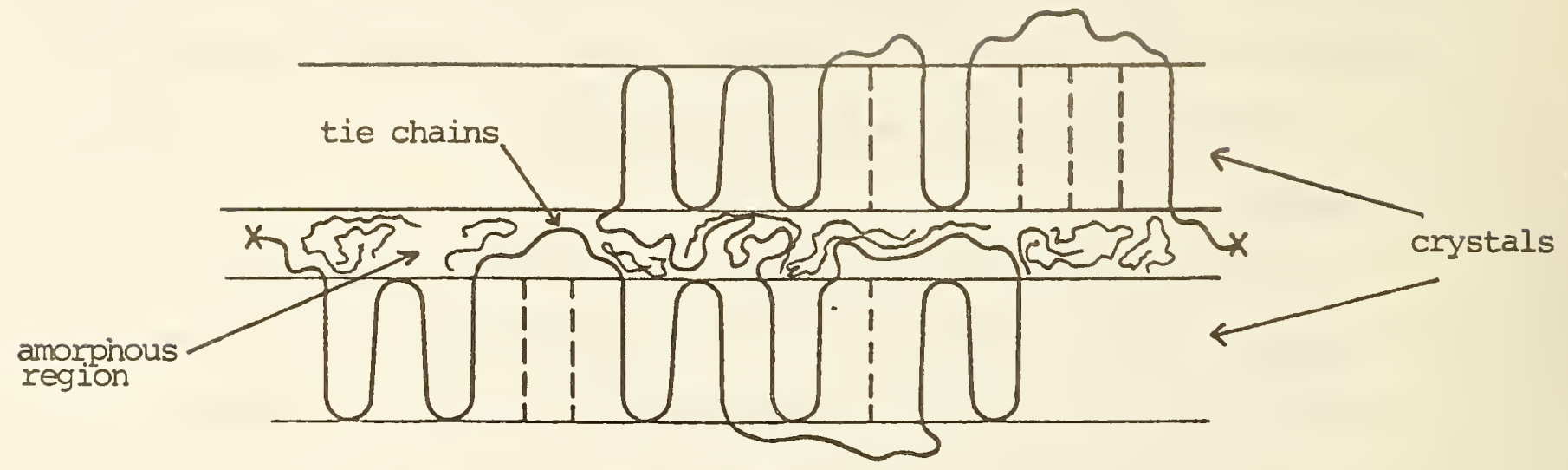

1. Semicrystalline polymer illustrating chain folded crystals, tie molecules, and the amorphous regions.

the other two dimensions grow very large in comparison. The thickness of polymer crystals is on the order of 50-200 \& [5]. This plate-like crystal structure is a major difference between crystals from polymers and nonpolymeric materials. Most polymers crystallize only in randomly distributed crystallites of microscoplc size.

Polymer crystals are surrounded by amorphous material but are connected by polymer chains that loop out of the crystal through the amorphous regions and participate in other crystallites. These tie chains give strength to the material by providing physical connections between the crystallites which hold the structure together.

The melting point, $\mathrm{T}_{\mathrm{m}}$, of a semicrystalline polymer is one of the most important characteristics governing its usefulness. $\mathrm{T}_{m}$ is influenced by $a$ number of characteristics of the repeating unit, the most important of which are: (1) structural regularity, (2) bonding flexibility, (3) close-packing ability, and (4) interchain attraction. High melting points are generally associated with either highly regular structures, rigid molecular structures, or a combination of these [4]. For example, 
PC has a high melting temperature, which is related to the molecular stiffness of the backbone which has two benzene rings.

A feature in the structure of amorphous polymers which affects mechanical properties is entanglements. The coiling motion of the polymer chains in the melt causes them to become entangled. However, a critical molecular length is necessary before the entanglements affect flow. Once chains are long enough to become entangled, flow becomes much more difficult because forces applied to one polymer chain become transmitted to and distributed among many other chains. Below the critical molecular weight, $M_{W}$, polymer viscosity is roughly proportionately to the weight average molecular weight, $\overline{\mathrm{M}}_{\mathrm{W}}$. Above the critical molecular weight, polymer viscosity is related to $\bar{M}_{W}$ raised to about the 3.4 th power [6]. The relationship between flow viscosity and $\bar{M}_{W}$ is illustrated in figure 2. For most polymers, the critical molecular weight is between $-10,000$ and 40,000 [6]. Since the viscosity increases as the molecular weight increases, more energy is required to process high molecular weight polymers. Thus an optimum range based on processability is usually selected for commercial polymers.

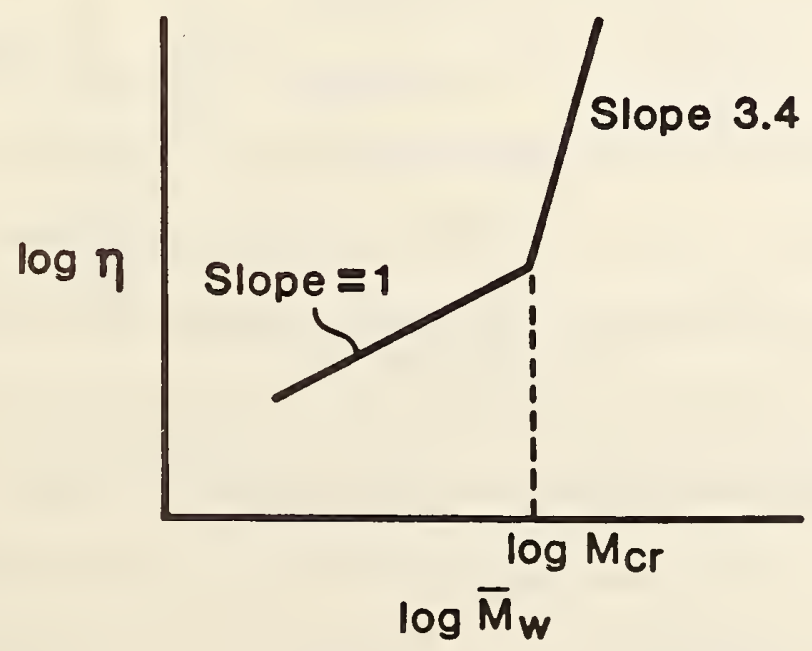

2. Flow viscosity as a function of molecular weight. 


\subsection{Glass Transition}

Most polymers have a characteristic glass transition temperature, $\mathrm{T}_{\mathrm{g}}$, above which the thermal motion of the polymer molecules is increased. This is important in cover plate applications since mechanical properties of polymers show profound changes in the region of the glass transition temperature. For this reason, knowledge of the $\mathrm{T}_{\mathrm{g}}$ can be vital in selecting a polymer for applications in which mechanical properties are important [7]. Above $\mathrm{T}_{g}$, the continuous vibrational motion of segments of amorphous chains results in a myrlad of different shapes of the polymer chain and, if the chain is long enough, the motion enables it to form physical entanglements with itself and its neighbors. Below $\mathrm{I}_{\mathrm{g}}$, the thermal energy is insufficient to activate movement of chain segments [8]. The $\mathrm{T}_{\mathrm{g}}$ is related to chain stiffness and the geometry of the polymer chain. The practical uses of varlous polymers depend greatly on their $\mathrm{T}_{\mathrm{g}}$ value. The main requirement for a polymer to serve as a useful plastic at room temperature is that $\mathrm{T}_{g}$ for amorphous polymers and $\mathrm{T}_{\mathrm{m}}$, in the case of crystalline polymers, occur well above room temperature. The $\mathrm{T}_{\mathrm{g}}$ is always less than $T_{m}$. An approximate empirical relationship of $1 / 2<T_{g} / T_{m}<2 / 3$ (with temperature in $K$ ) has been developed [9].

The segmental motion above $\mathrm{T}_{\mathrm{g}}$ is temperature dependent and $1 \mathrm{t}$ is the basis for polymer viscoelasticity [8] which implies behavior similar to both viscous liquids and to purely elastic solids. In viscous systems all work done on the system is dissipated as heat whereas in elastic systems all work is stored as potential energy as in a stretched spring [7].

The relative importance of the various deformation modes changes with the temperature, and it is convenient to distinguish four physical states of polymers, although in practice the divisions are not always clear cut. Starting at the low temperature end, the states are: (1) glassy, 
(2) retarded highly elastic (leathery), (3) instantaneous highly elastic (rubbery), and (4) viscous [10]. In the glassy state ideally there is only normal elasticity, although in reality some creep will be found. Above $\mathrm{T}_{\mathrm{g}}$ the glassy state gives way to the leathery state where thermal agitation is sufficient to promote retarded high elasticity and viscous flow. About 30 degrees above $\mathrm{T}_{\mathrm{g}}$ the leathery state merges into the rubbery state where the motion of molecules as a whole becomes dominant and where viscous flow rate occurs at an increased rate. Finally, at still higher temperatures the viscous flow rate increases to a point at which it dominates the other deformation modes. Below $\mathrm{T}_{\mathrm{g}}$, the material is a hard, rigid glass. As the temperature is increased for high molecular weight polymers, the material becomes leathery, then rubbery, and finally liquid. Only the $\mathrm{T}_{\mathrm{g}}$ is well marked, the other divisions being somewhat intermediate due to overlapping of the deformation modes [10]. Polymers are normally used at temperatures which put them into the glassy or leathery state. The load versus deformation curves for glassy,

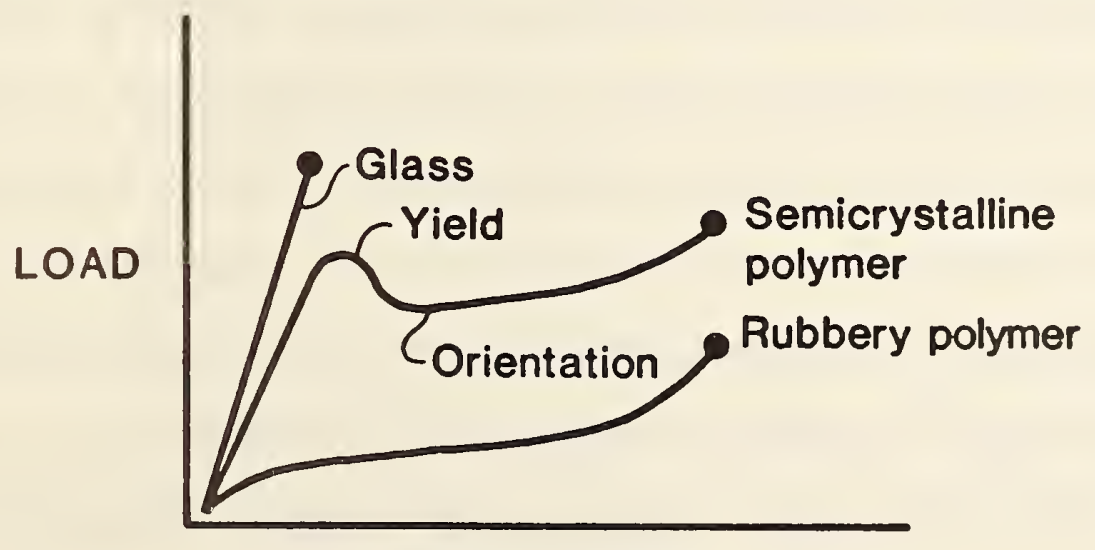

\section{ELONGATION}

3. Load-elongation curve for glassy, semicrystalline, and rubbery polymers. 
semicrystalline, and rubbery polymers are illustrated in figure 3 . One can observe the change in elongation as the temperature is increased from below to above $\mathrm{T}_{\mathrm{g}}$.

\section{Polymeric Cover Plate Materials}

The polymers used most frequently in cover plate applications are listed in table 1, along with their chemical repeat unit, glass transition temperature, and melting temperature. A brief description of each material follows.

Poly(vinylidene fluoride) is a semicrystalline polymer with a degree of crystallinity ranging from 35-65 percent, depending on thermal history [11]. The symmetric arrangement of the $H$ and $F$ atoms attached to the $C$ backbone contributes to the ease of crystallization. $\mathrm{T}_{\mathrm{m}}$ of commercial fllms is about $170{ }^{\circ} \mathrm{C}[11,12]$, although it depends on the method of polymerization and/or crystallization history. The $\mathrm{T}_{\mathrm{g}} 1 \mathrm{~s}-45^{\circ} \mathrm{C}$. PVDF $1 \mathrm{~s}$ extruded Into flims whlch can be orlented to increase mechanlcal strength. Cover plate fllm is about $0.13 \mathrm{~mm}$ thlck. PVDF has high levels of mechanical and impact strength, abrasion resistance, resistance to most chemicals and solvents, and reportedly has good resistance to sunlight.

Poly(vinyl fluoride) is a tough, flexible semicrystalline polymer having one fluorine atom on every other carbon atom in the backbone. Since $F$ has a Van der Waals radius near that of $H$, the regularity of the main chain is retained and PVF readily crystallizes. The degree of crystallinity ranges from 20-60 percent, depending on the polymerization method [13]. The melting temperature is about $200{ }^{\circ} \mathrm{C}$ [13] and the maximum continuous use temperature is $107^{\circ} \mathrm{C}$ [14]. PVF polymer is converted to film by melt extrusion. As a cover plate it is used in thicknesses of about $0.1 \mathrm{~mm}$. The extruded film can be biaxially oriented to varying degrees to improve tensile strength, tear resistance, and impact 
resistance. Because of the high temperatures needed for processing, heat stabilizers are added to PVF; however no plasticizers are used [14]. PVF has exceptional resistance to water adsorption, chemical attack and unusual solvent resistance. PVF has low solubility in all solvents at temperatures below $100{ }^{\circ} \mathrm{C}$ and is reported to have excellent resistance to damage from sunlight. However, the early PVF cover plate films discolored and embrittled [15]. Apparently the combination of elevated temperature and sunlight caused degradation. Inhibitor systems in PVF have since been altered.

Fluorinated ethylene propylene (FEP) is a semicrystalline copolymer produced by copolymerization of tetrafluoroethylene and hexafluoropropylene. FEP has a crystalline melting temperature of $290^{\circ} \mathrm{C}$ and $\mathrm{a} \mathrm{T}_{\mathrm{g}}$ between $-5^{\circ}$ and $29{ }^{\circ} \mathrm{C}[12,16]$. The continuous use temperature of FEP is $204^{\circ} \mathrm{C}$ [16]. FEP cover plates are made from extruded film having a thickness of about $0.025 \mathrm{~mm}$. The crystallinity of FEP after processing depends on the cooling rate of the molten polymer but can reach 70 percent [16]. FEP is a relatively soft material with lower tensile strength, wear resistance, and creep resistance than many polymers. Its strength decreases with increasing temperature. FEP is chemically inert to essentially all industrial solvents and chemicals and is virtually unaffected by sunlight.

Poly(methyl methacrylate) used in cover plates is an amorphous polymer with a $\mathrm{T}_{\mathrm{g}}-105{ }^{\circ} \mathrm{C}$. The bulky side groups off the main chain raise the $\mathrm{T}_{\mathrm{g}}$ and decrease the regularity, preventing the polymer from crystallizing. The maximum recommended use temperature is about $80-85{ }^{\circ} \mathrm{C}$ [17] which can present a problem for certain cover plate applications. PMMA cover plate materials are made by a casting process. Since it is a glassy material which is fairly brittle at ambient temperature, the thickness of PMMA 
cover plates is generally $1-1.5 \mathrm{~mm}$ or greater to provide sufficient strength to span across the collector. Prolonged subjection to even quite low stresses can produce surface crazing [17]. Differences in temperature and/or humidity on the inner and outer surfaces in glazing may bow the sheet in the direction of the higher value. Temperature differences act rapidly, within a few hours, but recovery is also fast when the gradient is removed. Differences in humidity act slowly over weeks [17]. Although PMMA has a history of good resistance to outdoor weathering, UV stabilizers are added to improve resistance to sunlight [18]. When cleaning a cover material the chemical resistance must be considered. PMMA is chemically resistant to many liquids, however aromatic and chlorinated hydrocarbons, ethers, and ketones attack it.

Poly(ethylene terephthalate) is a thermoplastic polyester which has varying degrees of crystallinity, depending on its thermal treatment [19]. The $T_{g}$ is reported as $69^{\circ} \mathrm{C}$ and $T_{m}$ as high as $280^{\circ}$, although the $T_{m}$ of most commercial products ranges from $255-265^{\circ}$ due to reduced crystallinity resulting from chemical impurities [20]. In semicrystalline PET both crystalline and amorphous regions contribute to the overall properties and a range of degrees of order exist. In the absence of nucleating agents and plasticizers, PET crystallizes slowly and performs best in applications where strength and crystallinity can be increased through orientation which is accomplished by stretching the film and inducing a high level of molecular chain alignment and extension. Orientation significantly improves creep resistance, tensile strength, and modulus. If an oriented film is heated above its $\mathrm{T}_{\mathrm{g}}$, additional crystallization may occur; thus PET cover plates may increase crystallinity if the temperatures exceed $70{ }^{\circ} \mathrm{C}$. Oriented PET has good chemical resistance being resistant to most organic solvents and mineral acids [21]. Unaged PET is 
a tough, strong film, however its properties degrade substantially on weathering. PET used as a cover plate has a thickness of $0.13 \mathrm{~mm}$ and is made by an extrusion process. PET is particularly susceptible to hydrolysis which can result in decreases in molecular weight and assoclated reductions in mechanical properties [20]. Upon exposure to sunlight, PET loses elasticity, breaks easily and develops a crazed surface. It is common for both UV and heat stabilizers to be added to PET or for UV absorber to be applied on the surface.

Polycarbonate used in cover plates is an extruded polyester based on bisphenol A. The $\mathrm{T}_{\mathrm{g}}$ is about $150^{\circ} \mathrm{C}$, however, due to the size and flexibility of the repeat unit and vibrational motion of parts of the chain, PC does not become brittle until $-100^{\circ} \mathrm{C}$. Polycarbonate crystallizes only after lengthy annealing at $190^{\circ} \mathrm{C}$ in the absence of oxygen and moisture [22]. Thus it is unlikely that cover plates contain crystalline PC. However, PC can crystallize from amorphous material by treatment with swelling agents or their vapors. Polycarbonate is soluble in or swelled by a number of aromatic and chlorinated hydrocarbons and other chemicals. With solar collectors it may be necessary to assure that heat transfer fluids and cleaners are compatible with the polymer. PC also exhibits some hydrolytic sensitivity [23]. The heat distortion temperature is $135-140{ }^{\circ} \mathrm{C}$ [22]. Annealing below $\mathrm{T}_{\mathrm{g}}$ leads to an increase in order and in stiffness [22]. Stresses can be removed by annealing above $100^{\circ} \mathrm{C}$. PC is a tough, stiff, impact resistant material, however it is not scratch resistant. Scratch resistant coatings have been developed [24]. Strong sunshine combined with humidity causes superficial yellowing and embrittlement to fracture. Thus thermal and UV stabilizers are added to PC $[24]$. 
Fiber reinforced plastics (FRP) are generally thermosetting polyester resins with glass fiber added for strength. Due to the highly crosslinked nature of these thermosets, they have no $\mathrm{T}_{\mathrm{g}}$ or $\mathrm{T}_{\mathrm{m}}$. FRP impact resistance and strength are alded by the presence of chopped glass fibers. As with most polyesters, FRP materials are generally susceptible to moisture damage and they are discolored by exposure to heat.

\section{Deformation and Mechanical Properties of Polymers}

Mechanical properties of a polymer are those properties involving loading or deformation of the material under the influence of applied forces. Polymer mechanical properties are complex because of their viscoelastic nature. Viscoelastic behavior is demonstrated by a strong dependence of the mechanical properties on time and temperature [1]. A brief overview of the deformation of polymers and their mechanical properties is provided here. The reader is directed elsewhere for more detailed discussions of polymer deformation and mechanical properties $[7,10,24-40]$.

\subsection{Polymer Deformation and Fracture}

When a polymer system is subjected to an applied stress, a number of chemical and rheological events (often having opposing effects) may occur at a given temperature. The net effect of the several competing processes depends on many factors, including the temperature, the time scale of the experiment with reference to the time scale of the process, the environment, the basic molecular properties of the polymer, and the composition [35].

At sufficiently low stresses and strains, the mechanical response is reversible while at higher stresses and strains an irreversible component of deformation becomes evident. Thus, during deformation and fracture, a variety of events takes place, including homogeneous shearing, 
heterogeneous shearing (shear banding), dilatational processes, and bond rupture [35]. Polymers exhibit a wide range of elastic properties depending upon their structure and the testing conditions. Figure 4 shows the variation of Young's modulus, E, with temperature for an amorphous polymer. At low temperatures the polymer is glassy with a relatively high modulus. The modulus falls rapidly through the region of the $\mathrm{T}_{\mathrm{g}}$ where the polymer is viscoelastic and the modulus is very rate- and temperature-dependent. At a sufficiently high temperature the polymer becomes rubbery. If the polymer is crosslinked the modulus remains approximately constant with increasing temperature, otherwise the polymer flows like a viscous liquid [33].

Semicrystalline polymers behave like amorphous polymers below the $\mathrm{T}_{\mathrm{g}}$ of the non-crystalline phase. However, they have interesting and useful properties between $\mathrm{T}_{\mathrm{g}}$ and $\mathrm{T}_{\mathrm{m}}$ where the structure consists of crystals in a rubbery matrix. The modulus of the material depends upon the degree of crystallinity and degree of orientation. The modulus values for different types of polymer are summarized in table 2 [33].

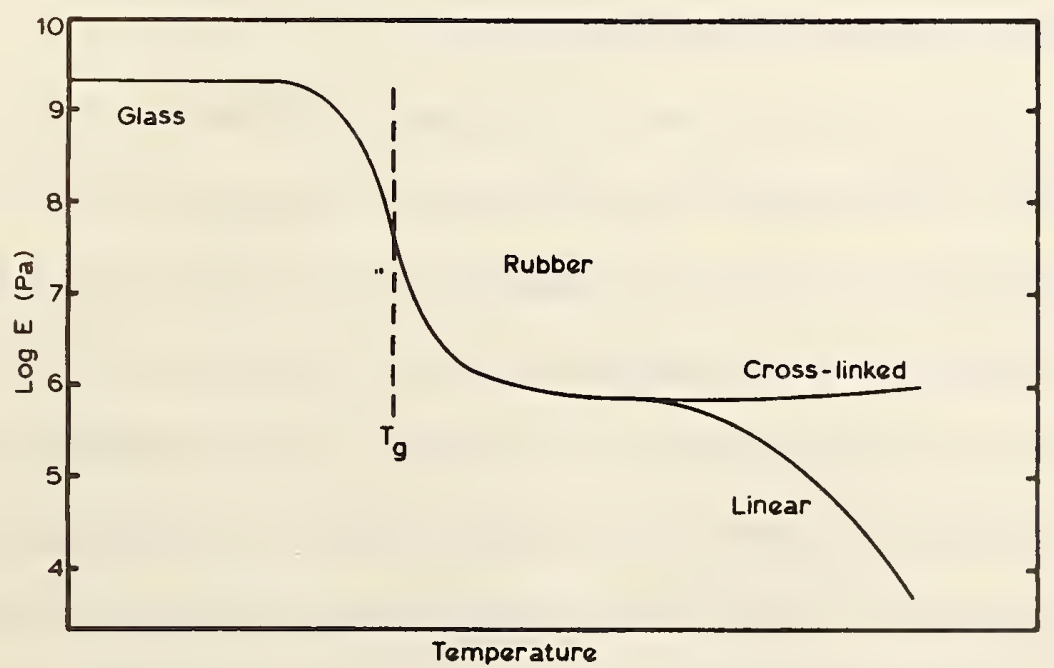

4. Typical variation of Young's modulus, E, with temperture for a polymer showing the effect of crosslinking upon $E$ in the rubbery state [33]. 
Typical Values of Young's Modulus, E, and Fracture Strength, $0_{1}$, for Different Types of Polymers Measured at Room Temperature and Moderate Testing Rates [33]

Type of Polymer
Modulus

$\mathrm{E}(\mathrm{MPa})$
Fracture Strength

$\sigma_{i}(\mathrm{MPa})$
Rubber

Semicrystalline

polymer (above $\mathrm{T}_{\mathrm{g}}$ )

Semicrystalline

polymer (below $\mathrm{T}_{\mathrm{g}}$ )

Glassy polymer
$-1$

$-100$

$-1000$

$-1000$
$-10$

$-30$

- 50

Two major deformation micromechanisms of importance in polymers are shear yielding and crazing. They represent the main source of energy absorption in the material. Both involve localized, or inhomogeneous, plastic deformation of the material. The difference between the mechanisms is that shear yielding occurs essentially at constant volume whereas crazing occurs with an increase in volume. Thus, unlike shear yielding, crazing is a cavitation process.

Ductile plastics tend to have a fairly well-defined yield point with the value of yield strain typically of the order of 5-10 percent--much higher than the value for metals or ceramics. Some semicrystalline polymers can be cold-drawn to extension ratios in excess of 20 during which a stable neck extends along the specimen. Most amorphous glassy polymers are brittle in tension but yield and flow to high strains in compression or pure shear [33]. Shear deformation consists of a change of shape without significant change in volume. Molecules translate past each other during shear yielding. The shear yielding of polymers is highly 
relevant to the mechanics and mechanisms of polymer fracture. Shear yielding limits the strength of the polymer if brittle fracture can be suppressed. A polymer must have a high yield stress in order to be strong and if bulk, homogeneous yielding does occur the polymer is likely to be tough. Recent evidence suggests that shear yielding, in the form of microshear bands, plays a key role in the initiation of cracks. Brittle crack propagation in polymers usually involves localized viscoelastic and plastic energy dissipative processes occurring in the vicinity of the crack tip [33].

A craze is initiated when an applied tensile stress causes microvoids to nucleate at points of high stress concentrations in the polymer created by scratches, flaws, cracks, dust particles, molecular heterogeneities, etc. The microvoids do not coalesce to form a true crack since they become stabilized by fibrils of plastically deformed, oriented polymeric material spanning the craze. The resulting localized yielded region therefore consists of an interpenetrating system of voids and polymer fibrils.

Molecular entanglements play an important role in controlling craze geometry. Unlike a crack, a craze is capable of transmitting loads between its faces. However, when cracks do initiate and grow, they do so by means of the breakdown of the fibrillar structure in a craze. This typically results in slow cavity expansion followed by crack extension through the craze, and finally crack propagation during which a craze or crazes precedes the crack tip through the remainder of the material [33]. Crazes may initiate, grow and break down to give cracks at stresses below those necessary to cause bulk shear yielding and so lead to brittle fracture requiring only a relatively low value of fracture energy, $G_{I C}$, or stress-intensity factor, $\mathrm{K}_{\mathrm{Ic}}$ [33]. Crazing therefore plays an important 
role in determining the strength of a polymer. Temperature is important in determining the balance between crazing and shear response. The relationship between yield stress, crazing stress, and microvoid nucleation stress for polystyrene is shown as a function of temperature in figure 5. Both the crazing stress and yield stress decrease as temperature rises. More detailed discussion of the mechanisms of crazing and shear yielding is given in references [33] and [35].

Whatever the detailed yielding response may be, attainment of the critical energy for crack propagation depends on the balance between energy stored and energy dissipated and, hence, on the relative importance of the various modes of deformation and their consequences in terms of strength of the molecular aggregations that oppose the crack's progress [35]. Many possible combinations of deformations and defects may exist thus making mechanistic correlations difficult. While fracture mechanics may serve to characterize a material, a given level of behavior may arise from a multiplicity of different competing molecular events [35]. The

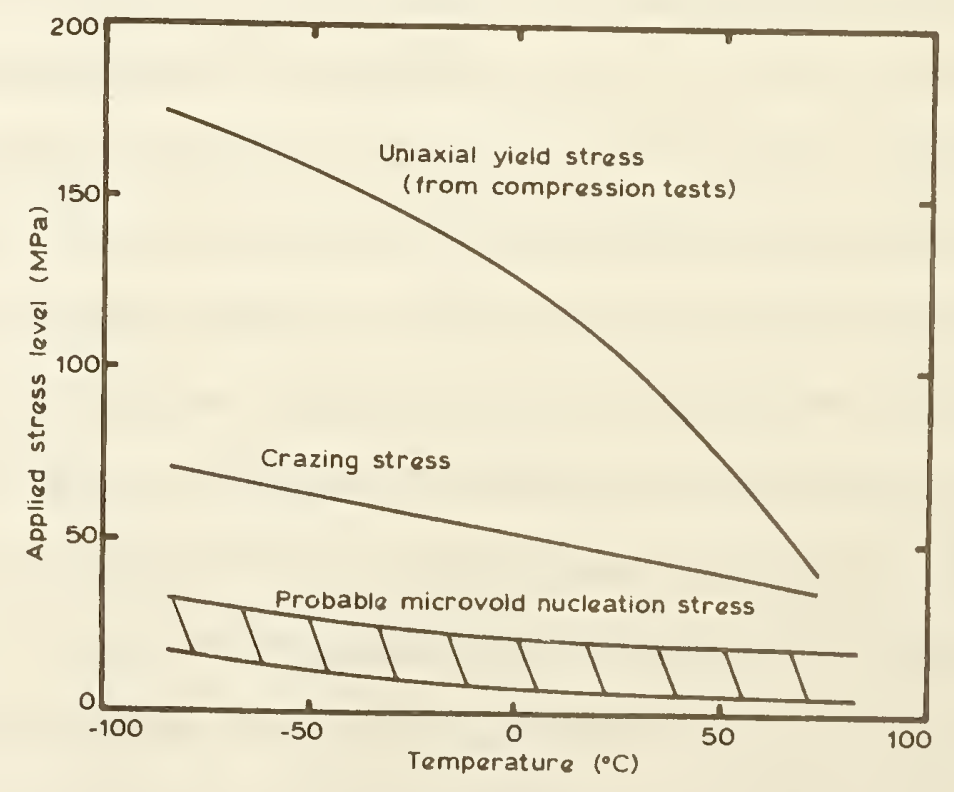

5. Relationship between yield stress, crazing stress, and microvoid nucleation stress in polystyrene [33]. 


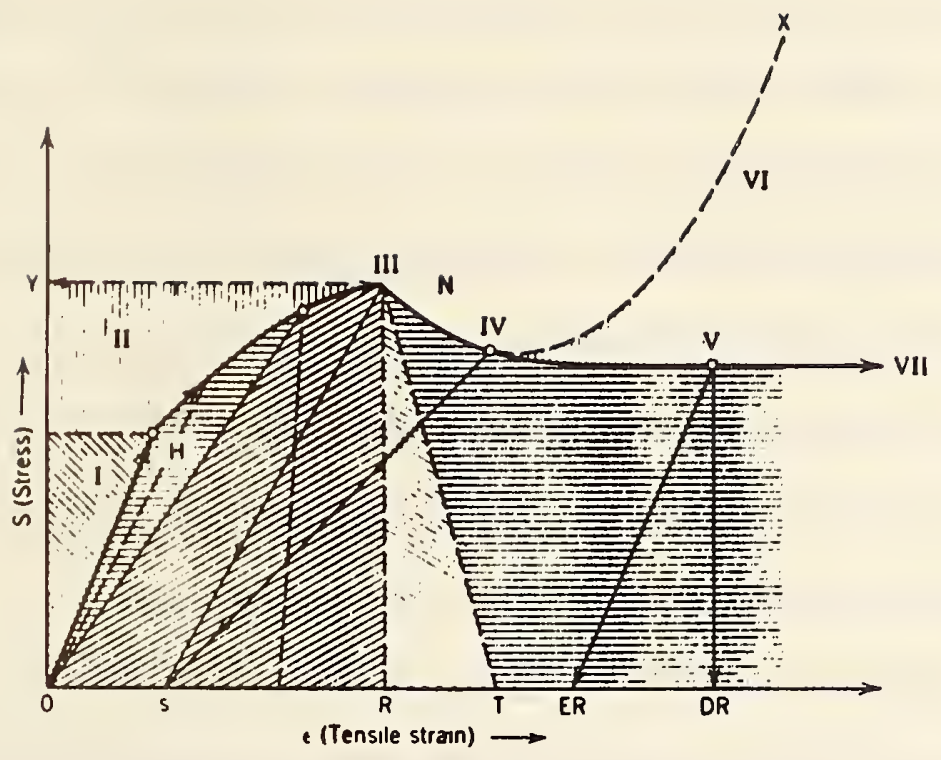

6. General deformation for a polymer: stress-strain curve as observed in one material as a function of temperature of rate of strain, or for a wide variety of materials. (I) Hookean elasticity; also linear viscoelasticity; (II) nonlinear viscoelasticity; (III) yield point; (Y) yield stress; (H) hysteresis of return curves; (N) necking region; (IV) beginning of strain hardening; (S) set, permanent deformation, incipient failure; ( $R$ ) rupture; ( $T$ ) tearing; (V) plastic flow; (ER) partial elastic recovery, elasticoviscous, or plasticoelastic; (VI) strain hardening and rupture; (DR) ductile rupture (VII) ductile failure [35].

general deformation of a polymer in simple tension is illustrated in figure 6 , and as shown, the response may be quite complex. The events shown have been described by Hertzberg and Manson [35] as follows.

"At first (Region I) bonds are stretched and energy is stored in a quite reversible manner (Hookean elasticity, linear viscoelasticity). As the stress rises further, the response (Region II) becomes nonlinear; energy is still recoverable on release of the stress, but slowly (anelastic response). Eventually, yielding occurs (Region III), accompanied by the onset of components of irreversible deformation. (This is not to say that no reversible component exists in this region; up to some point, even crazes may exhibit a high degree of reversibility.) During such deformation, extensive cooperative sequential motions take 
place, and energy is, of course, dissipated in a viscous manner. The nominal stress, then, usually drops somewhat (Region IV) and extension frequently proceeds easily, often with the formation of a neck that continuously undergoes drawing. Fracture (Region V) may occur shortly after necking begins or, especially with crystalline polymers such as polyethylene, fracture may be delayed due to an orientation of the molecules (analogous to strain hardening in metals) and the stress may actually increase, as shown in Region VI."

Polymer ductility decreases as the stress field becomes increasingly severe. Ductile/brittle transitions are due to competition between a brittle fracture mechanism such as crazing and a ductile mechanism such as bulk shear yielding. Fracture originates from local concentrations of flaws, scratches or notches. All materials contain such inhomogeneities which can propagate to cause failure. Crack propagation occurs when the material can deform or flow no longer, 1.e. When the limit of non-fracture deformation mechanisms is reached. The fracture stress, ${ }_{0} f, c a n$ be related to the crack length, a, by using a modified Griffith fracture equation [33] where

$$
{ }_{\sigma_{f}}=\left(\frac{E G_{c}}{\pi a}\right)^{1 / 2} \quad \text { for plane stress }
$$

where $G_{C}$ is the fracture energy and $E$ is Young's modulus. The fracture energy is the energy required to form a unit area of crack. A material's fracture strength may be characterized as the energy per unit area required to produce new surfaces. Polymers tend to have lower fracture strengths than metals and ceramics; typical values of fracture strength, for different plastics are given in table 2. As with Young's modulus, there is a wide variation. The concepts of fracture mechanics provide a sound basis on which to describe polymer fracture. In some areas, such as 
slow crack growth in glassy polymers, there is quite a bit of information, while in other areas, such as environmental crack growth and fatigue there is little. Ductile failure is the most difficult to characterize [40].

The experimental methods used to characterize crack growth generally employ quite large flaws or cracks and it is easy to use the data to predict what will happen when similarly large defects are present. However, when the flaws present are small, it is more difficult. Information is scarce and this area w1ll require more attention in the future. The theories of molecular fracture were originally developed without any direct evidence that molecular fracture actually occurs. Techniques are now available to study molecular fracture directly. The polymer fracture process can be broken down into three distinct steps:

1. The excitation of bonds under the action of an applied stress;

2. The scission of the excited over-stressed bonds by thermal fluctuations; and

3. The formation of small submicrocracks or crazes which coalesce to form larger cracks [33].

Experimental techniques are now available to study all phases of fracture. The most widely employed technique has been electron spin resonance spectroscopy (ESR) which can be used to follow scission. It allows the direct observation of free radicals produced when covalent bonds are broken. It is an extremely powerful technique which allows the number and the chemical nature of the radicals to be determined. Other experimental techniques have included infra-red and Raman spectroscopy, small-angle $x$-ray scattering, and the measurement of molar mass variations [33].

\subsection{Mechanical Properties}

The mode of fracture is related to the manner in which the load or force is applied to the polymer. There are at least five conditions of stress and environment that cause fracture. The five conditions, which 
correspond to various types of mechanical tests, are: (1) direct loading, (2) fatigue, (3) creep, (4) wear and abrasion, and (5) environmental stress cracking [31]. Direct loading involves applications of a stress unt 11 fracture is produced. Tens1le, compression, and 1mpact tests are examples of direct loading. Tensile and compression tests determine the capac1ty of a material to withstand stat1c load [42]; they are performed as stress-strain tests which provide information on the modulus (stiffness), strength, and elongation of the polymer. A sample tensile stress strain curve is shown in figure 6 .

Toughness is an indication of the energy a material can absorb before breaking. Ductile materials that cold draw are very tough due to the large elongation to break, whereas brittle materials have low toughness. Tensile properties of brittle materials are greatly influenced by flaws and submicroscopic cracks. Tensile properties of several cover, plate materials are listed in table 3 in the order of their tensile strength [41].

Impact resistance is a measure of toughness under shock loading [42]. Impact tests measure the energy necessary to fracture a material by an impulse load and provide an indication of notch toughness or notch sensitivity resulting from internal stress raisers. Two important factors Which enter into impact behavior are the energy needed to initiate a crack and the energy required to propagate a crack.

Fatigue is a measure of lifetime under cyclic loading [42]. It is a function of stress, consequently as one increases the maximum stress per cycle, the number of cycles to failure decreases. Fatigue fracture occurs after many cycles even though the maximum stress applied during a cycle is less than would be required to produce fracture under direct loading. 
Table 3

Tensile Properties of Several Cover Plate Polymers [41]

Polymer

Tensile Strength

$\mathrm{MPa}$

Elongation Tensile Modulus

at Break GPa

$\begin{array}{llcc}\text { Poly(vinyl fluoride) } & 48-103 & 100-190 & 2 . \\ \text { Poly(vinylidene fluoride) } & 48 & 300 & 1.4 \\ \text { Poly(methyl methacrylate) } & 55-76 & 2.0-7.0 & 2.4-3.4 \\ \text { Polycarbonate } & 55-66 & 60-100 & 2.4\end{array}$

Below some value of maximum stress, known as the fatigue or endurance limit, the fatigue curve levels off, and the material can be subjected to many cycles without failure [25]. Fatigue life generally decreases as the temperature increases and the frequency of oscillations increases. Fatigue failure is usually due to the gradual growth of cracks. Materials generally contain flaws which develop into submicroscopic cracks as the stress exceeds some critical value. The cracks grow a small amount during the peak load of a cycle until one or more of them exceeds microscopic dimensions. Fatigue life of polymers is also related to their mechanical damping and the resulting heat build-up in the material, if the heat produced is greater than the rate of heat dissipation. The strength of polymers generally decreases with temperature and crack growth becomes easier.

The dimensional stability of polymers is measured by creep and stress relaxation tests [7]. Creep tests measure the continuing deformation of a material with time as the load is held constant. Creep is a function of stress and temperature. Stress relaxation is the time dependent decrease in the stress of a material which is constrained to a constant 
deformation. Where viscous flow occurs the stress can decay to zero at sufficiently long times, however where there is no viscous flow the stress decays to a finite value.

Wear is the unwanted progressive loss of substance from the surface of a material brought about by mechanical action from the rubbing of one surface against another [43]. Abrasion, wear, and scratch resistance are all similar and are closely related to friction. The ploughing component of frictional force is especially important in abrasion and in the process of scratching a surface. It is similar on a microscopic scale to tearing [25]. Small particles of the material are torn or broken off the wearing or abraded surface.

Environmental stress cracking (ESC) is induced by the interaction between a polymer and a nonsolvent in the presence of mechanical stress. ESC occurs when crack or craze growth is promoted by the presence of an environment and a stress. The major part of the energy required for fracture is provided by chemical or physical-chemical processes, and the applied stress plays a secondary, though essential role [31]. Internal residual stresses may be sufficient to induce stress cracking in the absence of an external stress. The exact mechanism of ESC is not known, but the most likely mechanism appears to be that the presence of stress and a crack or flaw results in a local microvoided zone or craze at the crack tip and it is the interaction within this zone which gives enhanced crack growth. Fatigue and deterioration of polymers are frequently attributable to ESC. 
5. Effect of Microstructural and Molecular Factors on Mechanical

Properties

The deformation of a polymer is dependent on internal material characteristics as well as external environmental factors. The following microstructural and molecular factors influence the mechanical properties [7].

1. Molecular weight

2. Crystallinity and crystal morphology

3. Crosslinking and branching

4. Copolymerization

5. Plasticization

6. Molecular orientation

7. Residual stress.

Their effects on mechanical properties are discussed below. In addition to these, the following environmental or external variables are important in determining mechanical behavior [7]:

1. Temperature

2. Type of deformation (shear, tensile, biaxial, etc.)

3. Time, frequency, rate of stressing

4. Pressure

5. Stress and strain amplitude

6. Heat treatment or thermal history

7. Nature of surrounding atmosphere

8. Weathering.

The effect of temperature was discussed briefly in Section 3.4. The type of deformation will be considered below. The other factors will not be addressed. 


\subsection{Molecular Weight \\ 6.1.1 General}

The molecular weight and molecular weight distribution of a polymer have a large effect on mechanical properties. Commercial polymers contain molecules having a broad distribution of chain lengths. The molecular weight distribution (MWD) of polycarbonate is shown in figure 7 . The curve labeled o month illustrates the MWD for an unweathered material. The width and shape of the distributions are established during processing. The molecular weight is typically reported as an average value which obscures any knowledge of the distribution. The width and shape of the distribution are important because some mechanical properties are governed by the number of short molecules while others are dependent on the long chains. In general, as the molecular welght increases, the span of the molecular weight distribution increases. The narrower the molecular weight distribution curve, the more rapid is the increase in

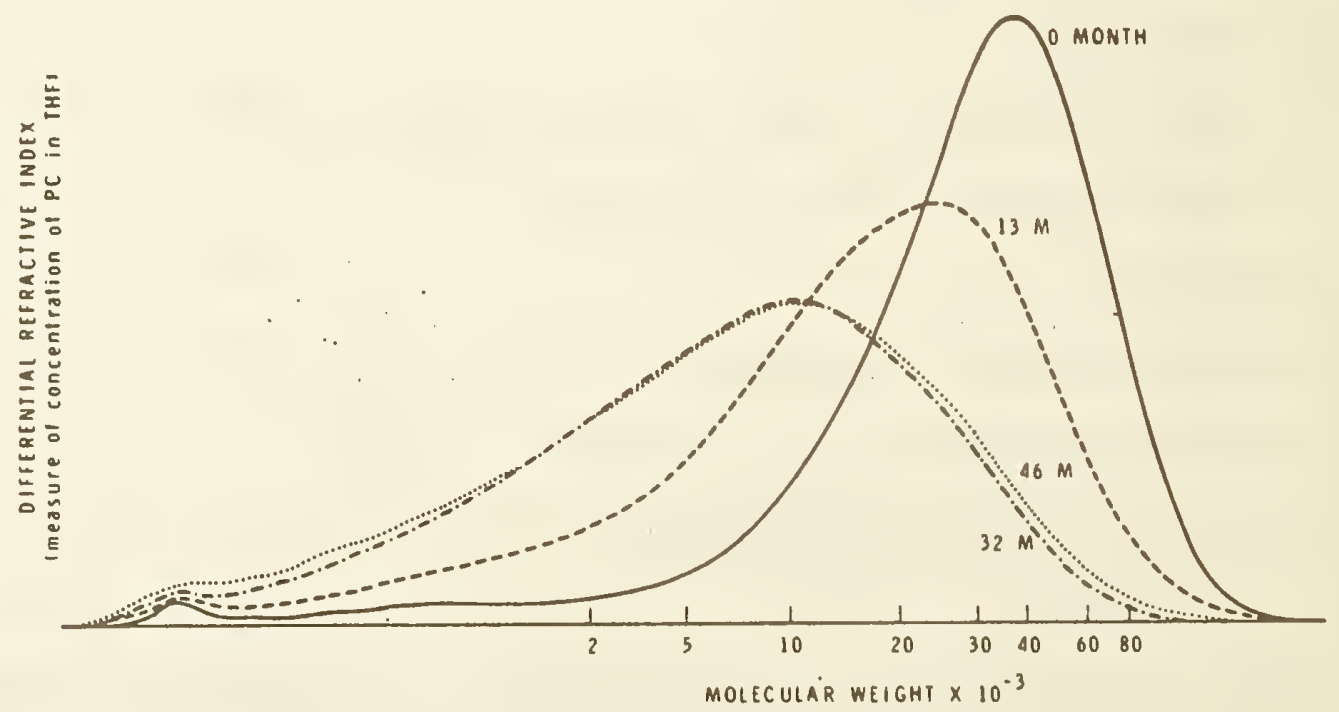

7. Molecular weight distribution of the irradiated surface layer of polycarbonate at various periods of exposure ( 0 to 42 months) to outdoor weathering [44]. 
strength with molecular weight. Polymers of interest have molecular welghts that range from $10^{4}$ to $10^{6}$ and contain lengths (1.e., of the fully extended molecule) that range from 0.1 to $10 \mu \mathrm{m}[8]$.

It has been known for some time that the mechanical properties of linear polymers are dependent on molecular weight in the sense that the polymer does not develop any significant strength until a certain critical value of molecular welght is reached where entanglements occur. Molecular entanglement must take place before a polymer can carry a load. Above this critical molecular weight, mechanical properties increase until a second critical value of molecular weight is reached beyond which the dependence of mechanical properties on average molecular weights is greatly reduced or nonexistent [10]. This point is illustrated in figure 8 . The exact shape and slope of the curve varies for different properties, as does the critical minimum molecular weight. The limiting value at high molecular weights will vary, depending on the specific polymer. Polar polymers and polymers with hydrogen bonding chains reach their maximum property values at lower molecular weights than do nonpolar

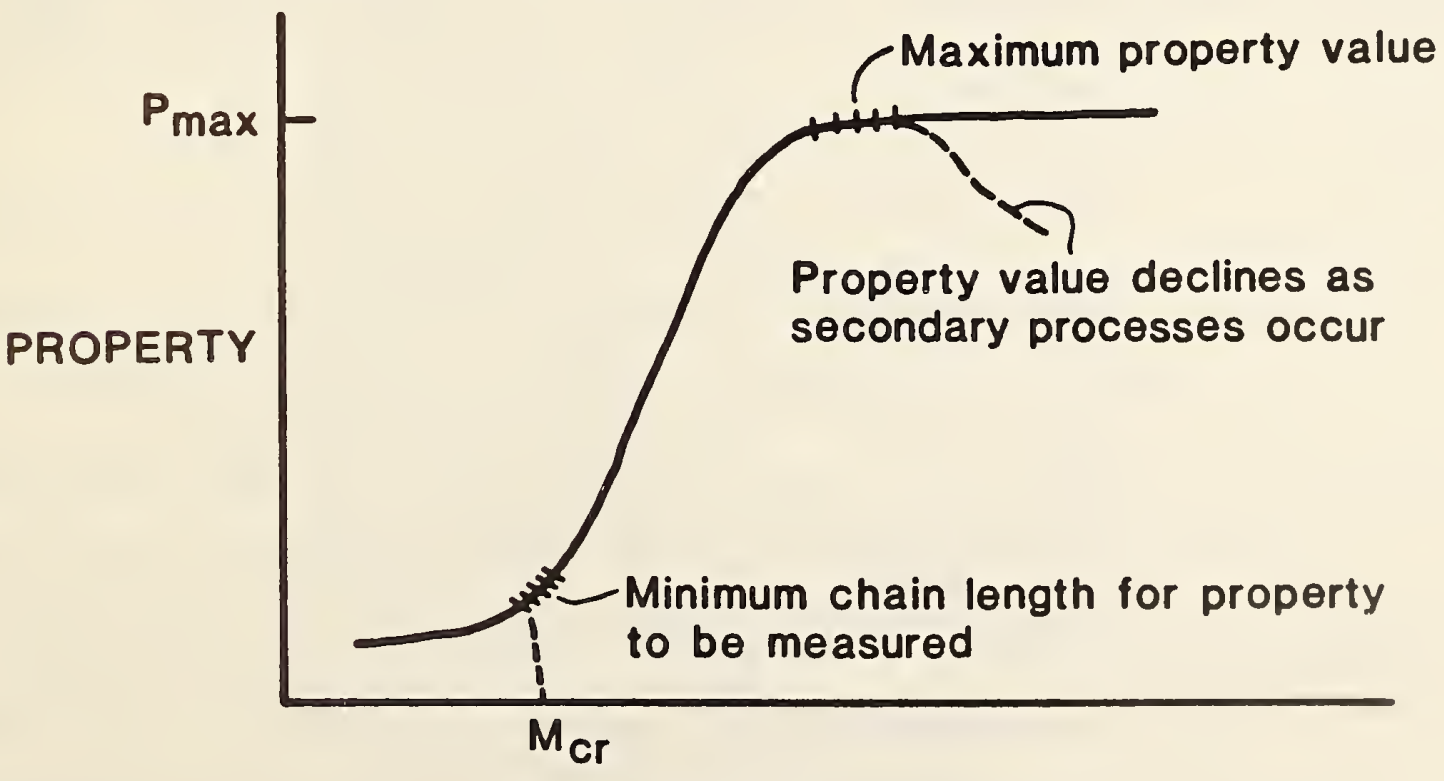

\section{MOLECULAR WEIGHT}

8. Relationship between molecular weight and polymer properties. 
polymers. For most thermoplastic materials, moderate ohanges in molecular welght do not appreclably influenoe mechanical properties such as yield stress or modulus. Thus, they must be toward the upper region of figure 8 . On the other hand, properties relating to rupture such as Ultimate elongation, impact strength, and ultimate strength are affected by moderate molecular weight increases. These must be toward the lower region of figure 8.

6.1.2 Effect of Molecular Weight on Mechanical Properties

An overview of the relationships between molecular weight and mechanical properties is provided here. A more comprehensive review is contained in references 45 and 46.

The molecular weight and molecular weight distribution of the polymer are probably the most significant microstructural features influencing deformation. The relationship between molecular weight and tensile or impact properties has been investigated for many polymers. The general conclusions reached are that the tensile and impact strengths and elongation at break increase to limiting values at high molecular weight.

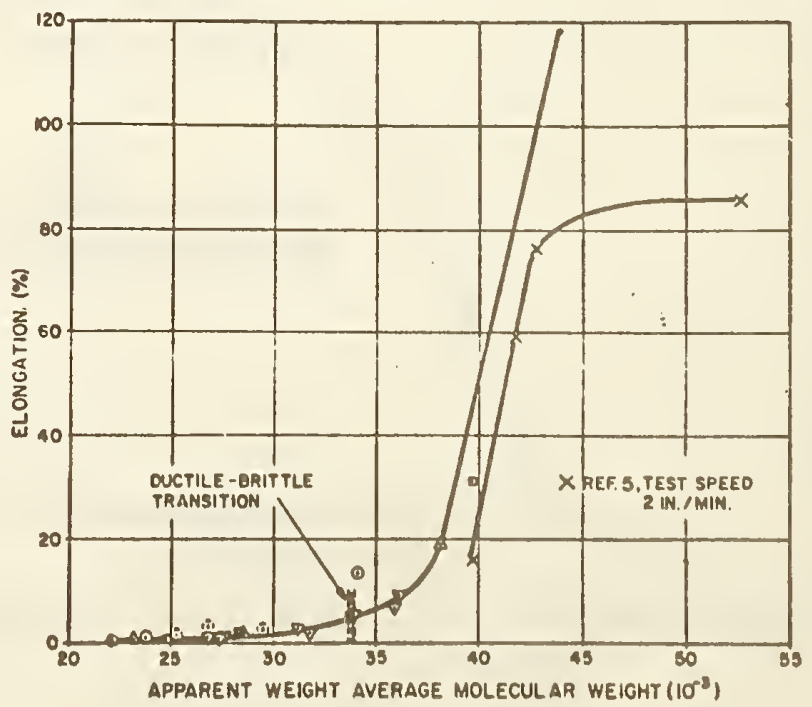

9. Elongation at break versus molecular weight for polycarbonate [46]. 


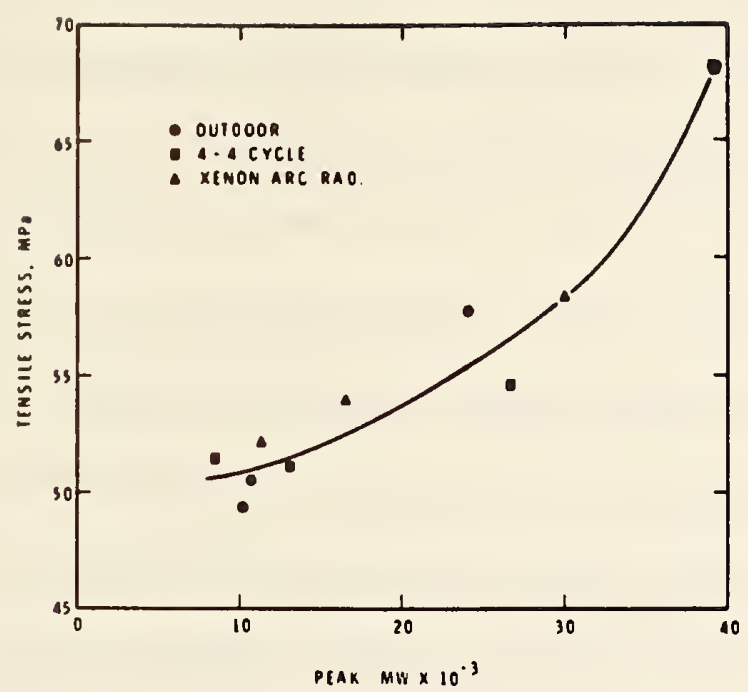

10. Tensile stress at break versus peak molecular weight of polycarbonate subjected to outdoor and artificial weathering conditions [44].

Yamasaki and Blaga [44] studied polycarbonate glazings and found that ultimate tensile stress and elongation at break decrease as molecular weight declines. Gardner and Martin [47] also obtained similar results. Figure 9 illustrates the relationship between molecular weight of polycarbonate and elongation at break while figure 10 shows the dependence of tensile stress on molecular weight.

Lee and Turner [48] found the density of entanglements for PMMA becomes significant only above a MW of $1 \times 10^{4}$ but eventually levels off above $1 \times 10^{5}$. Stress-strain properties of semicrystalline polymers such as polyethylene and polypropylene also depend on MW; however, this dependence seems to be less apparent because the crystallites help hold the material together, in much the same way as chain entanglements. Margolies [49] and Perkins et al. [50] examined high density polyethylene (HDPE) and found that the tensile strength increased with MW to $1.5 \times 10^{6}$, then leveled off. However Margolies found that the ultimate tensile elongation increased to a maximum at $5 \times 10^{5}$ to $7.5 \times 10^{5}$ but then 
decreased when the MW increased further. He concluded that the lower elongation values resulted when the ultra high molecular weight chain entanglement increased to a point where straightening was substantially inhibited prior to break. He also proposed that an increase in intermolecular forces between very high MW molecules became significant. Margolies also studied impact resistance of HDPE and found that Izod impact strength increased to a plateau then decreased gradually above $M W \approx 3 \times 10^{6}$. This is illustrated in figure 11. Apparently, the forces mentioned above that affect ultimate tensile elongation also affect impact strength.

Matsuoka and Wang [51] found that the MW of a polymer affects how much stress the material will be able to sustain beyond the yield point. Experimentally they found that the critical value for MW above which a polymer begins to sustain stress beyond the yield point is about equal to the critical MW for entanglement in melt rheology. In recent years the importance of the fatigue behavior of polymers has been acknowledged and work in this area is expanding. Little work has been done to explore the dependence of fatigue life and fatigue crack propagation (FCP) on MW [34]. From what has been done, it seems fatigue life increases as molecular

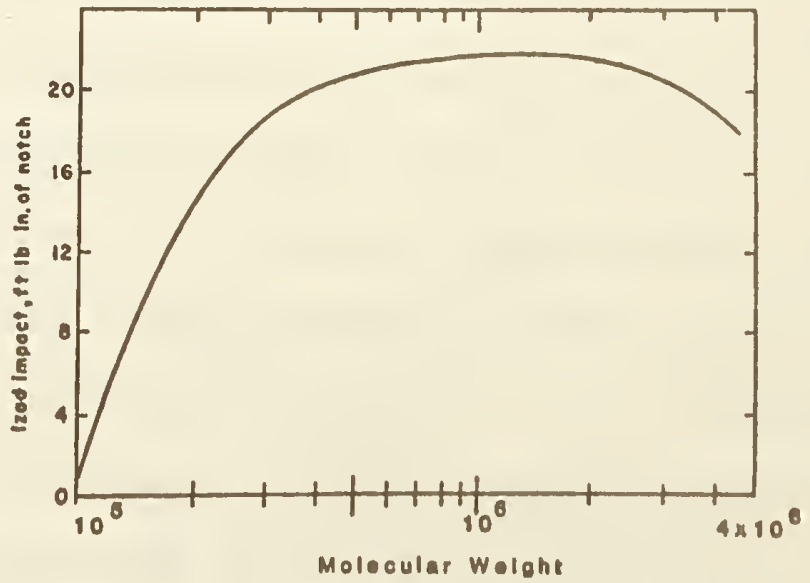

11. Izod impact of HDPE versus molecular weight [49]. 
weight increases. Pitman and Ward [52] found a substantial decrease in resistance of PC to FCP as the MW of the polymer decreased. Kim et al. [53] found that ECP rates of PMMA were dependent on MW even when fracture toughness changed little. Typical FCP curves showing the effect of MW of PMMA are shown in figure 12.

Michel et al. [54] have recently proposed a simple theory to explain the strong influence of MW on rates of FCP in amorphous polymers. They propose that ECP rates be expressed as the product of two functions, one involving the stress intensity factor $(\Delta K)$ and the other characterizing the relaxation process occurring in the plastic zone. To provide a physical network in the plastic zone that will sustain fatigue loading, they propose that one needs a sufficient fraction of molecular fibrils per unit area $\left(W^{*}\right)$ whose lengths are greater than $M_{c}$, the critical value of $\mathrm{MW}$ required for entanglement. They have correlated FCP data for PMMA using this approach. The effect of MW on fracture toughness is also of interest. From figure 13 it can be seen that values (converted to

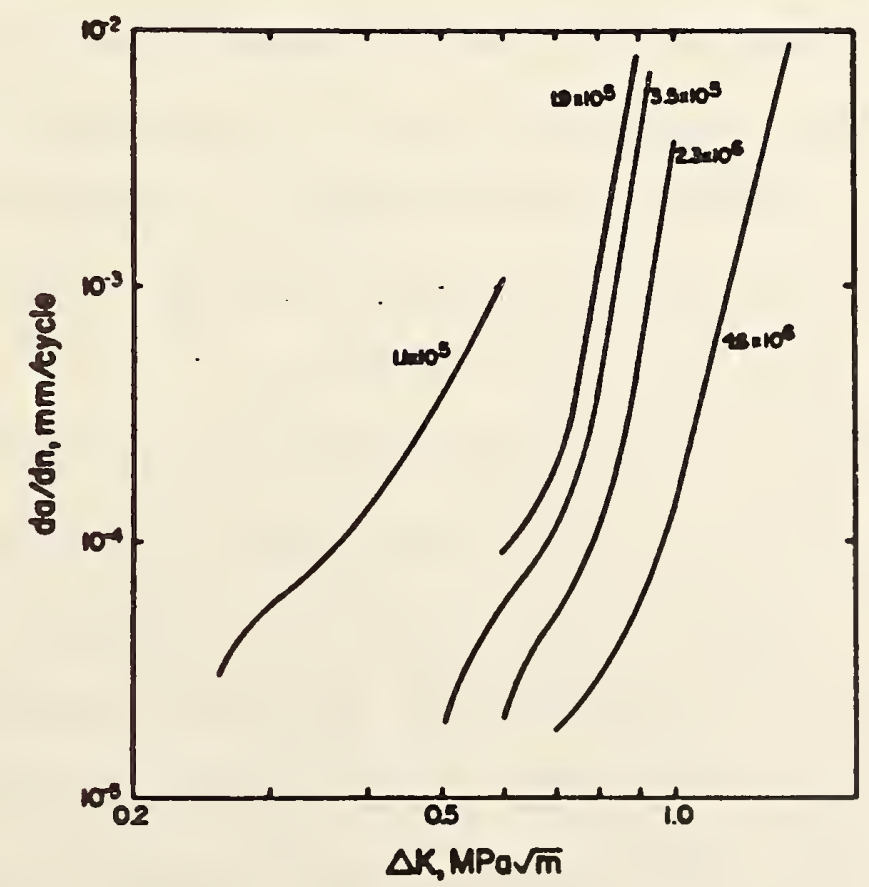

12. Typical FCP curves showing the effect of MW on fatigue crack propagation in bulk polymerized PMMA [53]. 


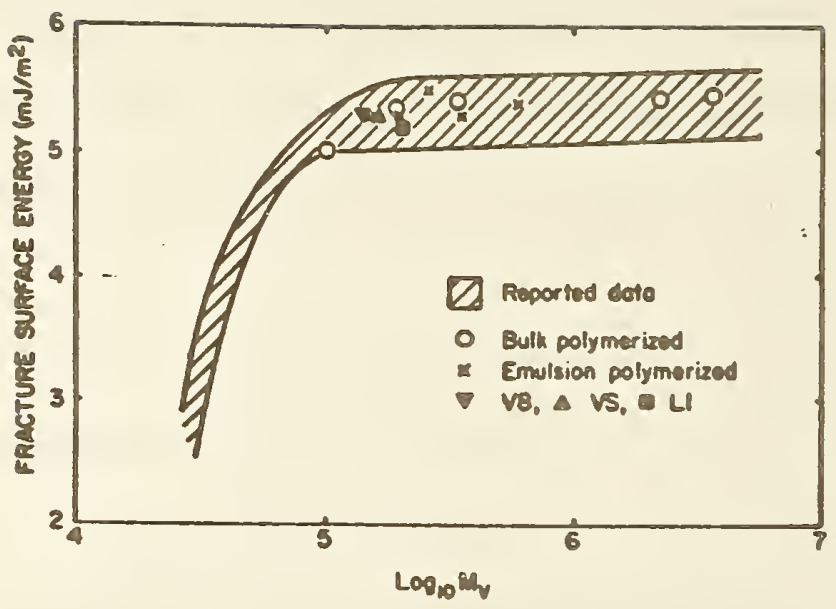

13. Effect of molecular weight on fracture energy of PMMA. Band indicates the range of values [53].

fracture energy) for all types of polymers are reasonably consistent. This also shows that fracture energy is fairly insensitive to MW above $\bar{M}_{v}-10^{5}$

The FCP response of some crystalline polymers such as PVDF is superior to that of glassy amorphous polymers such as PMMA. The substantial molecular reorientation, as evidenced by stress whitening at the fracture surface, may be important to the Improved FCP response of these crystalline materials [55]. For example, both PMMA and PC are amorphous and have similar elastic moduli, however, PMMA has a FCP growth rate 1300 times faster than found in PC [54].

Creep and stress relaxation are almost unaffected by changes in molecular weight below $\mathrm{T}_{\mathrm{g}}$ because the motions of the large segments in the polymer chain are frozen in place. Above $\mathrm{T}_{g}$ the behavior is strongly dependent on MW because the mechanical response of such materials is determined by their viscosity and elasticity resulting from chain entanglements. Bueche [56] found the creep compliance of PMMA is insensitive to $\mathrm{MW}$ in the glassy region, however at higher temperatures and/or longer times, creep and creep rate increase as the MW decreases. 
Apparently little has been done to study directly the

relationship between wear or abrasion resistance and MW. However, since abrasion involves tearing away of small pieces of material, the tensile strength and fatigue life are probably important factors. Both of them are improved by higher MW.

Environmental stress cracking (ESC) is not well understood and little has been done relating it to MW. ESC behavior is dependent upon the molar mass of the polymer, with lower molar mass material having the worst ESC resistance. Herman and Biesenberger [57] studied the relationship between molecular weight distribution (MWD) and ESC in annealed PE and found that a narrow MWD shows superior stress crack resistance to a polymer of similar average molecular weight but with a broader MWD. They conclude that the greater amount of low molecular weight material and a high molecular weight tail give rise to voids and stresses causing low ESC resistance in broad distribution resins. Devries et al. [58] found an 18 percent decrease in the MW of PET exposed to $\mathrm{O}_{3}$ for four days.

\subsection{Crystallinity}

The mechanical response of a semicrystalline polymers is related to the crystalline regions, the amorphous regions, and the tie chains which join the lamellar regions into a mechanically integrated structure. Tie molecules carry a high level of stress and are broken during deformation and fracture. The behavior of tie molecules may be compared with entanglements in amorphous thermoplastics--both are responsible for the strength of the polymers and without them both types of polymer are extremely weak. Figure 1 illustrates the crystalline/amorphous matrix of a semicrystalline material. A given polymer's tendency toward being crystalline or amorphous is determined by the chemical structure. The morphology of semicrystalline polymers and their degree of crystallinity 
have profound effects on their mechanical behavior. Since these factors can be varled over a wide range, the mechanical properties of semicrystalline polymers take on a perplexing array of possibilities [7]. Polymers do not attain complete crystalline order and the crystallization rate varies widely among polymers.

Crystallinity is generally favored by symmetrical chain structures that allow close packing of the polymer units to take advantage of secondary forces which are distance related. High interchain (secondary forces) interactions also favor crystallinity. The extent of the crystallization is limited by irregularities in the molecular structure of the polymer. Examination of the repeat unit of cover plate materials in table 1 illustrates these points. PVF and PVDF, which have fairly symmetric chain structures, are fairly crystalline, whereas in PMMA and PC the molecular structure is far less regular.

The degree of crystallinity is also affected by the rate at which the polymer melt is cooled during fabrication. If it is cooled rapidly, the polymer may solidify without reaching maximum crystallization.

Consequently, it may continue to crystallize at a very slow rate if the temperature is increased. Such a situation could occur on a solar collector where the cover plate is exposed to temperatures elevated above ambient. Crystallinity can also be increased in polymers by mechanically stretching to align and crystallize the polymer chains.

Unlike amorphous polymers the application of fracture mechanics to the fracture of crystalline polymers is not very straightforward even for isotropic materials. This is principally because crystalline polymers are not normally brittle and their deformation can be non-linear but it is also because there is often large-scale yielding in the vicinity of the 
crack tip. Hence it is generally impossible to apply linear elastic

fracture mechanics unless the polymer is at low temperature or has been embrittled through environmental action [33].

Isotropic semicrystalline polymers deformed at temperatures above the ${ }^{\mathrm{I}} \mathrm{g}$ of the amorphous phase are usually ductile, and they yield and flow forming a neck with the specimen often drawing up to 30 times its original length. Figure 6 illustrates the stress-strain curve of a typical polymer. The relative ease of plastic deformation means that semicrystalline polymers are generally tough above $\mathrm{T}_{\mathbf{g}}$ of the amorphous phase. Below the $\mathrm{I}_{\mathrm{g}}$ the amorphous phase is much less compliant and the semicrystalline sample has a higher yield stress but flow is unable to take place and so failure occurs at a lower strain [33].

Semicrystalline polymers are often so ductile that they can be deformed to very high draw ratios before the specimens fail. In these polymers, the noncrystalline component is normally rubbery; this allows the crystals to deform plastically and change shape without cleavage. During the early stages of deformation the original spherulitic structure becomes elongated through slip and other deformation mechanisms. The chain axes of the crystals which are originally oriented randomly become aligned parallel to the drawing direction. Eventually the original lamellar and spherulitic structures break up and a new fibrous structure is formed with the molecules aligned approximately parallel to the extension direction [33]. Semicrystalline polymers can be induced to behave in a brittle manner by reducing the temperature or using certain hostile environments. Fracture surfaces of HDPE deformed at liquid-nitrogen temperature appear relatively smooth when examined at low magnification but detailed studies [59] have shown that plastic deformation occurs on a local level even when 
the fracture appears to be completely brittle. Spherulite size has a pronounced effect on the deformation of semicrystalline polymers. The larger the spherulite size, the more brittle the polymer.

In semicrystalline polymers, the high molecular weight molecules crystallize first resulting in a molecular fractionation. Low molecular weight polymer accumulates at crystallite boundaries. Gedde et al. [60] recently showed that for polyethylene, fracture preferentially develops along the weakest link path defined by these regions of segregated low molecular weight material. It is likely that other semicrystalline polymers behave similarly.

On a higher level of morphology, there is still not yet any clear idea how factors such as crystal structure or spherulite size affect the behavior. A few studies have shown that, in general, large spherulites cause the polymer to be more brittle, but the micromechanisms are not yet fully understood. This may be contrasted with the studies of the behavior of glassy polymers where a great deal is known about the micromechanisms of deformation and fracture. This is clearly an area where more work needs to be done. Similarly, the application of fracture mechanics to ductile semicrystalline polymers is in its infancy, again in contrast to amorphous polymers and metals [33].

Impact resistance of semicrystalline polymers is generally better than that of glassy polymers. Semicrystalline materials have better fatigue resistance than amorphous polymers, probably because crystalline polymers not only dissipate energy when crystallites are deformed, but they also apparently reform a crystalline structure that is exceedingly strong [35]. In static fatigue, HDPE, a semicrystalline material, fails in a ductile manner after short loading periods whereas after prolonged loading it fails in a brittle manner [59]. For short loading periods the yield 
stress is less than the fracture stress and the polymer is ductile whereas for longer periods of loading the fracture stress is less than the yield stress and so the material is brittle.

The premature failure of semicrystalline polymers in certain aggressive environments is a long standing problem. ESC is characterized by brittle fracture. Williams and co-workers $[61,62]$ have found a unique dependence of crack velocity upon $K_{I c}$ for crack propagation in $P E$ in environments such as methanol, ethanol, and a detergent. This is illustrated in figure 14 for HDPE in hot $\left(60^{\circ} \mathrm{C}\right)$ detergent. Williams and Marshall [62] have interpreted the change in slope in the plot between $10^{-7}$ and $10^{-6} \mathrm{~ms}^{-1}$ as being due to a change in the fracture mechanism. They suggested that in the slow growth region the crack growth rate is controlled by viscoelastic "relaxation processes" in the material. However, at higher velocities it is thought that the different slope corresponds to crack propagation in this region being controlled by transport of the environment to the crack tip. They were able to

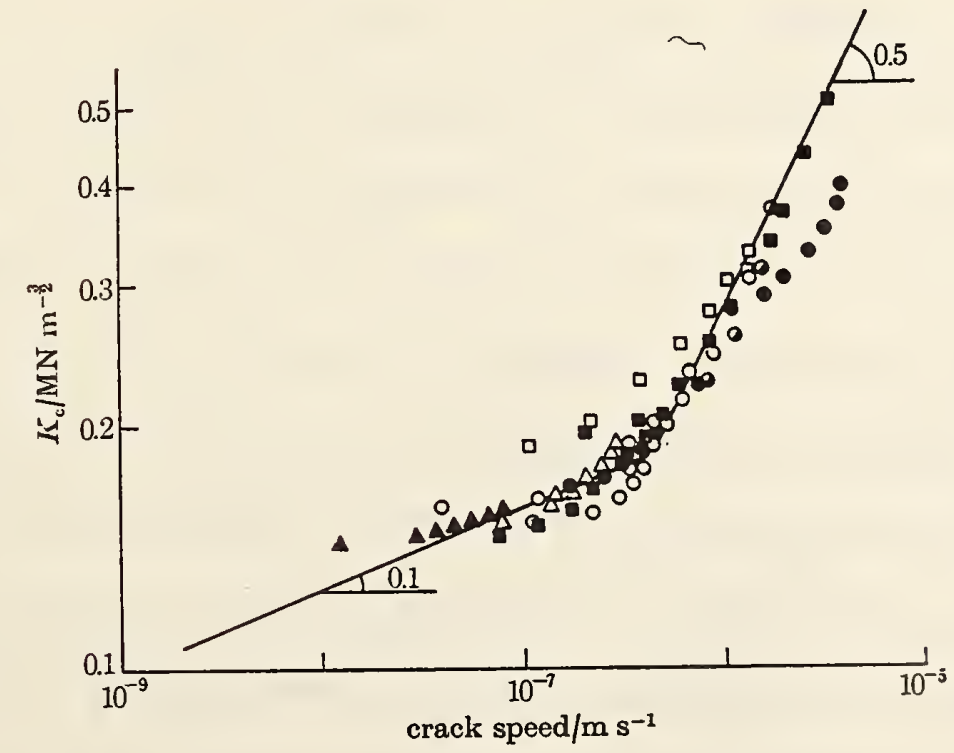

14. Crack growth data for high density polyethylene in a detergent environment at $+60^{\circ} \mathrm{C}$. (Different points represent individual tests) [62]. 
correlate the velocity at which the transition between the two types of behavior occurred with the viscosity of the fluid, with the transition taking place at the lowest crack velocities for fluids with the highest viscosity.

\subsection{Crosslinking and Branching}

Crosslinking is a chemical linking established between adjacent polymer chains which results in a three-dimensional network. Crosslinking provides stability to the physical shape of a polymeric object because when a load is applied, the crosslinks resist deformation. Rigidity of a polymer is increased by crosslinking, depending on the degree of crosslinking. The length of the crosslink and the distance between crosslinks varies. The shorter, the crosslinks, or the smaller the separation between them, the stronger and more rigid the polymer becomes. Lightly crosslinked polymers are rubbery whereas heavily crosslinked materials are rigid and may be brittle.

Branching occurs when the backbone of the main polymer chain has chains of identical chemical composition branching from it. The length and frequency of branching affects the properties of polymers. The branches provide increased physical entanglement between adjacent molecules and consequently increase strength and rigidity. However branching results in decreased regularity of the chain and of the polymer crystallinity. Branching is established at the time of processing and does not change during a polymer's life. Chain branching affects viscosity above $\mathrm{T}_{\mathrm{g}}$. The effect is difficult to quantify because the length and number of branches vary. Above $\mathrm{T}_{\mathrm{g}}$, crosslinking and branching in moderate amounts improve modulus, yield strength, flexural properties, fatigue life, shear, and impact properties while decreasing elongation to yleld, elongation to break, and creep resistance. Environmental stress cracking and wear abrasion also benefit. 
6.4 Copolymerization

Copolymerization results when two or more monomers are polymerized together so that the polymer backbone contains alternating sequences of one repeating unit then the other. Copolymerization is performed to modlfy polymer properties. Generally, copolymerization decreases crystallinity by introducing more irregularity. In addition, the $T_{g}$ is altered, with the $\mathrm{T}_{g}$ of the copolymer falling between the parent homopolymers. Copolymerization occurs during polymer processing and does not change during the life of the polymer.

FEP is the only cover plate material that is a copolymer. Its crystallinity is lower than that of poly(tetrafluorethylene) (PTFE) (1.e., 70 percent vs 98 percent). This 1 s a result in the loss in chain regularity from replacement of a fluorine atom by a perfluoromethyl group. The effect of copolymerization on mechanical properties depends on the polymers involved. By judiclous cholce of the type and structure of the monomers, a copolymer with specific desired properties can be designed.

\subsection{Plasticizers}

The addition of a plasticizer to a polymer is made to lower the glass transition temperature, thus increasing the flexibility and toughness of the material at ambient temperature. Plasticizers are low vapor pressure liquids, with molecular weights in the range of 100 to 1000 which form a highly concentrated solution with the polymer. The polymer chains in the amorphous regions are forced apart by the plasticizer decreasing the intermolecular forces between chains and allowing them to slip more readily over one another. The absorption of small molecules such as water or the entrapment of monomers has a similar effect to the addition of a plasticizer. In general, the addition of plasticizers decreases properties requiring strong interchain bonding such as tensile strength, flexural modulus, and yield strength. Properties assisted by chain 
flexibility and slickness such as elongation at break and elongation at yield are increased. Conversely, loss of plasticizer is indicated by increase in yield strength and a drop in ultimate elongation reflecting embrittlement of the polymer. It is believed that plasticization of the polymer by active chemical species plays a role in failure due to environmental stress cracking.

\subsection{Orientation}

Orientation can be produced by either hot stretching of a molten polymer followed by rapidly cooling of the melt, or by cold drawing, or by cold-rolling. Most commonly, orientation is accomplished by stretching the polymer at or above $\mathrm{T}_{\mathrm{g}}$. Fixing the orientation occurs when the stretched polymer is cooled below $\mathrm{T}_{\mathrm{g}}$ before the molecules have had a chance to return to their random orientation. Biaxial orientation occurs when a polymer is stretched in two directions at right angles to each other. The polymer chain segments tend to line up parallel to the plane of the sheet. Compared with unoriented materials, biaxially oriented sheets and films have higher tensile, tear, and impact strengths [62].

Typical tensile behavior of oriented brittle polymers is shown in figure 15. Parallel to the orientation direction, the polymer may become ductile and have a yield point and high elongation, but in the perpendicular direction the polymer becomes more brittle with low strength and elongation [25]. The tensile stress-strain behavior of ductile polymers is illustrated in figure 16. When an oriented polymer is tested in the parallel direction, it has a higher yield strength, but its elongation to break may be less than that of an oriented polymer tested in the perpendicular or transverse direction. The reason for this unusually high transverse elongation is that on stretching the previously oriented material in the perpendicular direction, the molecules first deorient and 


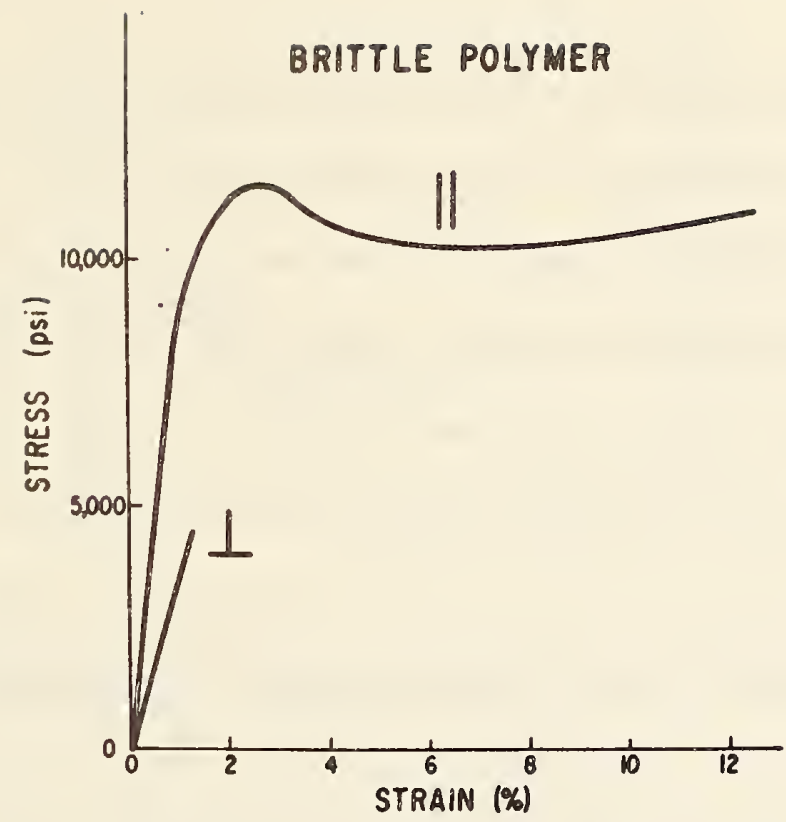

15. The stress-strain behavior of typical polymers which are brittle in the unoriented state. ||$=$ tensile stress parallel to direction of orientation. $\perp$ = stress perpendicular to the direction of the uniaxial orientation [25].

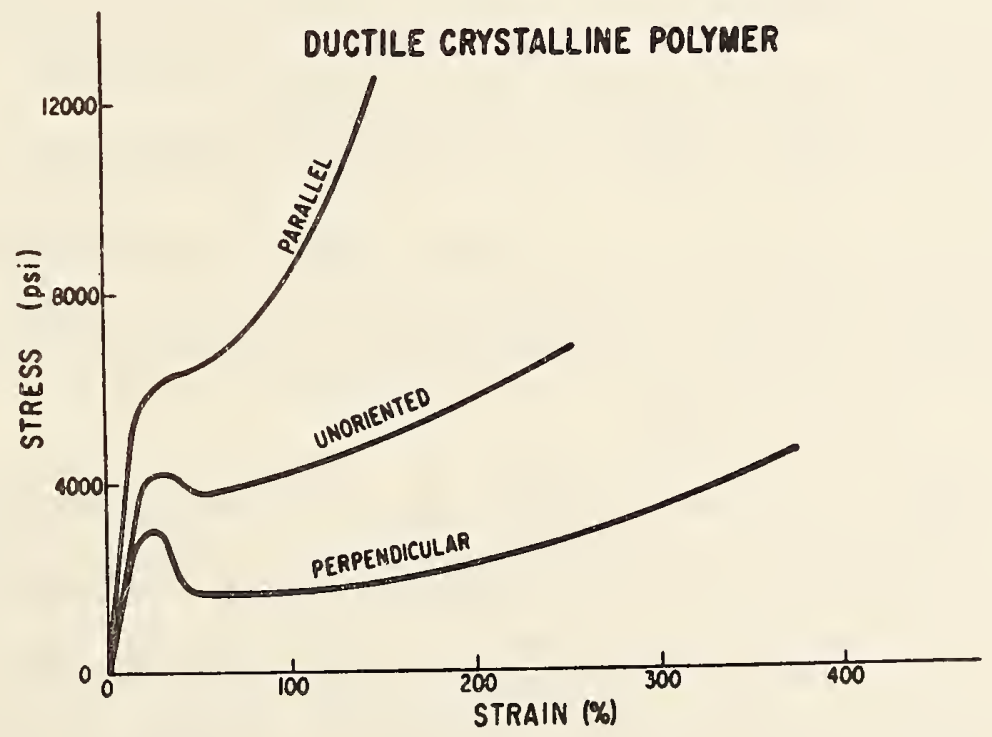

16. The tensile stress-strain behavior of ductile polymers: unoriented, measured parallel to the direction of uniaxial orientation, and measured perpendicular to the direction of the orientation [25]. 
then reorient in the direction of the applied force. Brittle materials break before the reorientation process gets started [25]. Polymers have high strengths and moduli in the direction parallel to the orientation because the applied loads are carried largely by the strong covalent bonds of the polymer chalns. The properties are poor (at least for brittle polymers) in the direction perpendicular to the orientation because the loads are carried primarily by the weak Van der Waals' bonds. Also, if there are small cracks or other imperfections in the polymer, they become oriented parallel to the orientation direction. These oriented cracks are strong stress concentrators for loads applied perpendicular to the orientation direction.

Broutman and McGarry [64] looked at biaxially oriented PMMA and uniaxially stretched PMMA. In the case of the blaxially oriented material cracks could be propagated in different directions perpendicular to the plane of the sheet with the interfacial fracture energy $G_{I c}-1300 \mathrm{~J} \mathrm{~m}^{-2}$, whereas cracks growing in the plane of the sheet propagated with $\mathrm{G}_{\text {Ic }}$ - $33 \mathrm{~J} \mathrm{~m}^{-2}$, showing clearly the relative ease of cleaving between molecules rather than across the molecules. $G_{I c}$ for isotropic PMMA was found to be $-250 \mathrm{~J} \mathrm{~m}^{-2}[64]$.

In the uniaxially stretched PMMA, G $G_{\text {Ic }}$ for crack propagation parallel to the orientation direction was found to drop as the degree of orientation was increased, falling by over an order of magnitude for polymer stretched by over 100 percent [64]. In similar studies by Curtis [65] on PMMA, It was found that $G_{I c}$ for crack propagation parallel to the orientation direction could be directly correlated to the birefringence of the oriented polymer, as shown for PMMA in figure 17. Again the value of $\mathrm{G}_{\text {Ic }}$ drops by over an order of magnitude for the most highly oriented samples [65]. 


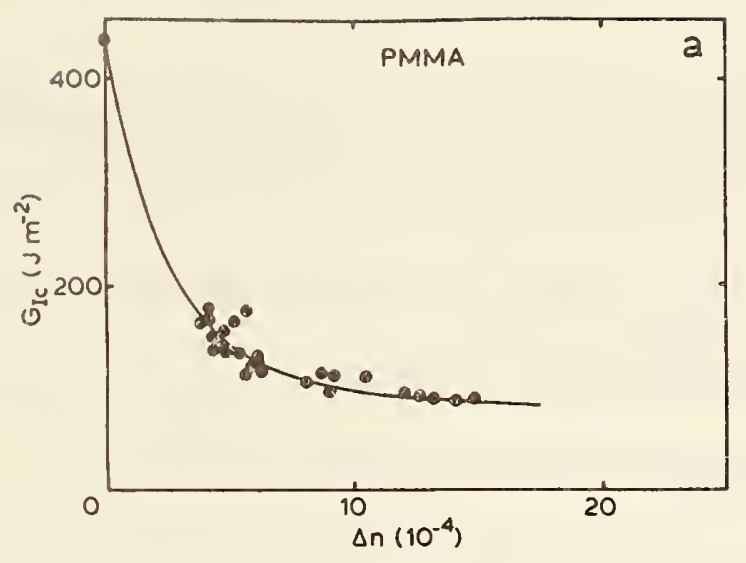

17. Variation of $G_{I c}$ in PMMA with orientation (given by birefringence, $\Delta \mathrm{n})$ for crack propagation parallel to direction of orientation [65].

PVF is an oriented semicrystalline film and PET and PVDF may also be oriented. When PVF film is heated above $100^{\circ} \mathrm{C}$, it shrinks three to five percent [66]. Oriented PVF film is sometimes placed on a frame and heat shrunk to cause the cover plate to appear taut. This practice places the entire film under tension and undoubtedly induces localized stresses. Since stressed areas are more prone to degradation, heat shrinking cover plate materials onto frames may hasten the polymer degradation.

\subsection{Residual Stresses}

During fabrication the polymer is subjected to both a definite thermal cycle and a definite shear cycle which vary considerably between the different methods of fabrication. The level of residual stresses in a fabricated material depends upon the response of the material to this combination of shear and thermal histories. They depend upon both the level of orientation induced at a specific point throughout the fabrication cycle and the opportunity for its relaxation during the remaining part of the cycie. The rate of relaxation at a particular temperature will also tend to decrease as the molecular weight increases, and, in a given fabrication process, both these factors will contribute towards a higher level of residual stresses. The improvement in 
mechanical properties usually observed with increasing molecular weight on isotropic specimens may not, therefore, be observed in a fabricated material, owing to this higher overall level of residual stresses [63]. An increase in molecular weight also results in an earlier onset of melt flow defects such as melt fracture. The magnitude of these residual stresses and flow defects can be minimized by increasing the temperature at which the deformation is carried out, but this inevitably results in a longer overall cycle which is economically undesirable. There are often additional restrictions on the upper temperature that can be used owing to side effects such as crosslinking or chain scission, development of odor, color changes etc., resulting from volatilization of additives and oxidation, which may be detrimental to the final performance and/or the appearance of the component. Some improvements can often be achieved by modifying the width of the molecular weight distribution, as the rate of decrease in viscosity with increasing shear rate is higher for wide distributions [63].

\section{Degradation of Polymeric Cover Plates}

The weathering which polymeric cover plates receive on solar collectors frequently causes degradation and a resultant loss of mechanical properties. The weathering and environmental parameters that supply the energy necessary for cover plate deterioration are shown in table 4. The first four parameters, i.e., UV radiation, oxygen, water, and temperature, will be considered here.

Polymer degradation may be considered any type of chemical change of a polymer involving the main-chain backbone and/or side groups. These changes require the breaking of primary valence bonds, leading to lower molecular weights, crosslinking, and cyclization. Although degradation is 
UV Radiation

Oxygen or Ozone

Water

Temperature

Active Chemical Environment

Chemical Pollutants

Particle Bombardment

Cyclic Loading
0.29 to $0.40 \mu \mathrm{m}$ wavelength range of sunlight $\mathrm{O}_{2}$ or $\mathrm{O}_{3}$ humidity, rain, snow, dew, frost, fog absolute value, thermal gradient, and thermal cycling heat transfer fluid contact

$\mathrm{SO}_{2}, \mathrm{NO}_{2}$, and $\mathrm{NaCl}$

dust, sand, hail, bird droppings, and insects wind, snow loads

a chemical process, not only is the chemical composition of the polymer modified, but also physical parameters such as MW, MWD, crystallinity, chain flexibility, crosslinking, and branching which are governed by the chemical composition.

The main processes taking place as dominant events during degradation are random chain scission, depolymerization, crosslinking, bond changes, and side group changes. The type of degradation occurring under a given set of circumstances is dependent upon the reaction rates. When multiple weathering factors are present, several degradative processes can be happening simultaneously.

Chain scission involves bond breakage in the main backbone of the polymer. Each chain scission creates another molecule and lowers the MW. Hydrolysis of a polyester (e.g., PET or PC) is an example of a random chain scission process since the susceptibility of the bond does not depend greatly on molecular size. Depolymerization is a chain scission occurring in the polymer backbone, generally from an end. During 
depolymerization molecules are repeatedly split of from the active end of the polymer chain reducing its length until the polymer molecule no longer exists.

Crosslinking occurs when the reactive end of a broken polymer chain reacts with the backbone of another polymer chain forming a chemical link to the second chain. Crosslinking entails a localized increase in density which creates internal stresses and the development of microcracks that embrittle a material and increase the surface area open to chemical attack.

Changes in the polymer backbone can be induced without scission or crosslinking. For example, when PVC is heated, a chlorine atom and an adjacent hydrogen atom react to form $\mathrm{HCl}$. Th1s changes the backbone structure to form a double bond which is more susceptible to free radical attack than the fully saturated material. A zippering occurs leaving behind successive conjugated double bonds. The remaining structure is highly reactive with metal salts and with oxygen. Since the chain cannot rotate around double bonds, it is stiffened even in the absence of crosslinking [67]. The atoms within side groups can react with each other to eliminate a molecule similar to the above reaction with PVC. Side group changes such as these are least important in contributing to degradation which affects the mechanical properties of polymers.

The three most dominant processes occurring during degradation in a solar collector (1.e., chain scissions, bond changes in the main chain, and depolymerization) result in shortened polymer chains meaning fewer entanglements per chain. This translates to less deformation resistance. On the other hand, crosslinking, which occurs less frequently, increases the connections between chains and provides greater resistance to deformation. During processing the material is subjected to very high thermal and mechanical stresses. These high stresses may initiate a 
varlety of polymer degradation processes leading to a deterioration of properties even during processing. On the other hand, the damaging of the material may result in the introduction of varlous defects in the polymer which will work as degradation sources during its subsequent service life. For example, in the presence of oxygen traces during processing, carbonyl groups can be formed. These will function as built in sensitizers for photodegradation processes [68]. Because of the dual nature of degradation during processing, i.e., deterioration and the introduction of defects as potential sources of deterioration, it is very important to add stabllizers to the polymer before processing.

Polymer degradation can occur either at the surface or in the bulk. Degradation from photooxidation, thermal oxidation, and hydrolysis are more severe at the surfaces. Damage at the surfaces occurs more readily through the combination of degradation mechanisms. Thus, in considering cover plate degradation, the surface exposed to the sun will undoubtedly suffer the most degradation because it is exposed to the greatest combination of factors.

Cover plate materials having an ester linkage $\left(\prod_{-C-0-)}^{0}\right.$ (1.e., PC, PET, and FRP) are subject to hydrolysis at the exposed surface which results in lowering of the MW. In semicrystalline materials, such as PET, hydrolysis occurs preferentially in amorphous regions. This is undoubtedly one of the reasons PET is reported to become brittle so rapidly [66]. Surface cracking has been reported in PC $[44,69,70]$, PET $[66,71]$, and FRP $[66,70-74]$. The thickness of PC and FRP as cover plates is $1 \mathrm{~mm}$ or greater, whereas PET is about $0.13 \mathrm{~mm}$. Thus, if surface degradation took place to an equal depth in all three, the PET would show loss of mechanical properties more rapidly because of the higher ratio of the volume of the damaged material to the total volume of material. The 
number of chains available to resist deformation is drastically reduced and fracture undoubtedly occurs through the amorphous regions where the tle chains linking the crystallites have been severed.

The major cause of degradation in PMMA is chaln scission caused by sunlight. This occurs at the outer surface and results in a reduction in MW. PC degrades through hydrolysis and photooxidation. Weathering studies of PC have shown a loss of $M W$ and tensile properties [44]. Figure 7 shows the downward shift in molecular weight distribution of PC with longer periods of weathering. Changes in elongation at break and elongation at yield of PC exposed to outdoor and natural weathering are illustrated in figure 18. The decline in elongations parallels the reduction in MW seen in figure 7.

PET degrades through both photooxidation and hydrolysis, and loses strength rapidly when exposed outdoors [66]. PVF and PVDF are falrly resistant to degradation from sunlight. Thermal degradation is probably the most important degradation mechanism. A likely mechanism of thermal degradation is abstraction of $\mathrm{HF}$ molecules in a manner similar to that

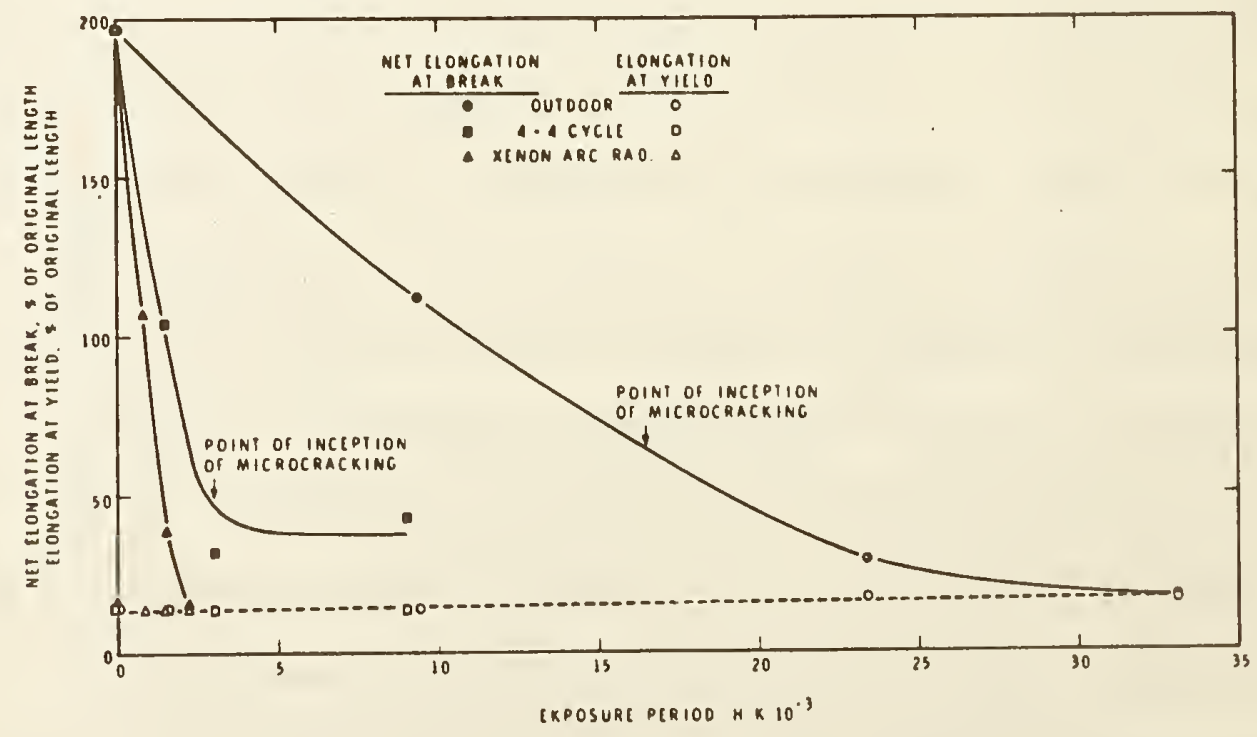

18. Changes in net elongation at break and elongation at yield of PC on exposure to outdoor and artificial weathering conditions [44]. 
described for PVC earlier, the result is a reduction in MW. Loss in tenslle strength and elongation at break for PVF have been reported [66].

The most common mechanisms of degradation affecting cover plate materials result in a reduction of molecular weight. Most frequently this degradation occurs at the surface. On a molecular scale, this means that the polymer molecules at the surface are less entangled because they are shorter than those in the bulk polymer, or not entangled at all if their length is short enough. (Short molecules may simply volatilize). Consequently the surface region is less capable of resisting deformation. On a macro scale, cover plate polymers can be subjected to small deformations on a regular schedule, such as daily thermal expansion and contraction, swelling through absorption of moisture followed by contraction at its loss, or motions due to wind. While these seem small on a macroscopic level, at the microscopic level these forces are applying a cyclic stress to the polymer. When the $M W$ is reduced so that it contains few entanglements and offers little resistance to deformation, small local regions readily deform and can initiate a microcrack at the surface. With additional degradation, the deforming stress is then concentrated at the crack tip and spread over a smaller number of chains than previously, resulting in continued crack growth.

Fukushima [75] has shown that the deterioration of polymer materials by the simultaneous action of UV-light and diffusive oxygen is a function of depth from the surface and increases in proportion to the square root of time. Thus, monitoring the MWD (i.e., loss of long molecules and gain of short molecules) as a function from the surface should show a degradation profile which can be related to a decline in mechanical properties. 


\section{Discussion}

\subsection{General}

Probably the single greatest consideration with respect to mechanical properties of polymeric cover plates is the fact that they decline during use due to degradation caused by weathering. Degradation is a chemical process affecting the composition and other physical parameters. The mechanical properties of polymers are dependent on a number of factors, some of which are inherent in the specific polymer while others are induced at the time of processing. The key factors relating to the polymer are: glass transition temperature, molecular weight and molecular weight distribution, crystallinity, crosslinking, copolymerization, and plasticization. These factors are not independent variables, rather their effects are frequently interactive and it is difficult to isolate the effects of each individually. Fabrication of the polymer into a product may introduce orientation, anisotropic (unwanted) residual stresses, flaws, melt flaw defects, or weak reactive sites in the chain structure. These factors are difficult to measure and will vary, depending upon the specific process involved, processing temperatures, and the polymer characteristics.

\subsection{Polymer Microstructure}

The glass transition temperature is the most important material characteristic of a polymer as far as mechanical properties are concerned because it determines whether a cover material reacts to an applied force in a brittle or ductile manner. The $\mathrm{T}_{\mathrm{g}}$ is related to the flexibility of the polymer chain structure and the presence of plasticizers. Plasticizer added during processing may be lost during use by volatilization due to heat or by leaching out by liquids. In some cases molsture or a chemically active environment may plasticize a cover plate material and lower the $\mathrm{Tg}$. The glass transition temperature can be measured in a 
variety of ways including dilatometry, refractometry, differential thermal analysis (DTA), differential scanning calorimetry (DSC), infrared spectroscopy, nuclear magnetic resonance (NMR), stress birefringence, dielectric constant and loss, creep and stress relaxation, and dynamic mechanical properties [76-78].

The molecular weight and molecular weight distribution are the most significant microstructural features influencing deformation. Higher molecular weight provides more strength through more entanglements in the amorphous material and through tie chains between crystallites in semicrystalline materials. The molecular welght of cover materials is reduced by polymer degradation, i.e., bond breaking, due to UV, heat, moisture, or mechanical stress during processing. The average molecular weight can be determined by many methods, the more common of which are intrinsic viscosity, light scattering, osmotic pressure, and gel permeation chromatography $[77,78]$. These methods require the polymer to be dissolved in a solvent which is difficult for some polymers. An alternative method for determining molecular weight, which does not require solvent, is a melt viscosity measurement [78]. This method is actually more sensitive in identifying small changes in average molecular weight. The most common method for determining molecular weight distribution is gel permeation chromatography $[77,78]$ which separates the polymer molecules by size. In some cases it may be very difficult to determine the molecular weight of cover plate materials if the material is not readily soluble or if the melt viscosity is too high to be measured in the temperature range of the melt rheometer. For example, the $\mathrm{MW}$ of poly(vinyl fluoride) is estimated by its producers at MW 1,000,000 because of its high MW and the difficulty in dissolving the polymer. The tendency for a polymer to crystallize is influenced by the regularity and flexibility of the polymer chain. The size of the crystallites and the 
extent of crystalization is generally determined by the rate of cooling, although orientation can also produce crystallization. The film cover plate materials are semicrystalline 1.0., PVF, PVDF, FEP, and PET. Crystalinity provides the film with strength and toughness. Crystallites contribute to deformation resistance by dissipating energy during deformation, but they probably also reform into a strong crystalline structure. Incomplete crystallization at the time of fabrication can lead to problems for cover plate materials later if the temperature is raised or the $\mathrm{T}_{\mathrm{g}}$ lowered to a level where polymer crystallization can occur. Such crystallization would result in a small volume change and induce stress into the material. Crystallinity is detected and its amount estimated by a number of methods: x-ray diffraction, infrared-absorption spectroscopy, polarized light microscopy, density, calorimetry, differential thermal analysis, and nuclear magnetic resonance spectroscopy [76-78].

Crosslinking occurs either at the time of processing or through polymer degradation. With the exception of the fiber reinforced polyester, the polymeric cover plates contain little, if any crosslinking at the time of processing, although degradation may induce some crosslinking at the surface. FRP is a thermoset material which is highly crosslinked. The degree of crosslinking dictates the rigidity of a polymer. Heavily crosslinked materials such as FRP are rigid and may be brittle, whereas lightly crosslinked materials are rubbery. Degradation of most polymers is likely to induce only light crosslinking. Because crosslinking essentially forms a large polymer network, crosslinked materials are insoluble, however they will swell when exposed to an appropriate solvent. Crosslinking is measured through swelling experiments or by analysis of the stress-strain curve of a polymer network $[78,79]$. This latter technique is not approprlate to characterize surface crosslinking as may occur in cover plate degradation. 
Fluorinated ethylene propylene is the only cover plate material which is a copolymer. Copolymerization is generally accomplished to selectively control some property of the end product. Once a copolymer is formed, it can be characterized in the same manner as other polymers.

Copolymerization offers one possibility of obtaining different materials for cover plates. By judicious choice of the monomers involved, it may be possible to design a copolymer with specific desired properties.

Plasticizers are added to polymers to lower $T_{g}$ and to increase the flexibility and toughness of the material. Cover plate materials probably have very little plasticizer added since plasticizers can be driven out by elevated temperatures. Water, in the form of humidity or moisture which collects on cover materials may be absorbed into the surface layer and act as a plasticizer that enhances the yielding processes which occur during degradation. Blaga [70] has postulated a theory for the mechanism of surface degradation of plastic based sheets, whereby surface microcracks are produced by differential dimensional strains induced by humidity and temperature, in conjunction with resin degradation.

Stresses in the cover plate, such as would result from orientation or from anisotropy introduced during processing, can be measured with birefringence, infrared dichroism, and polarization of fluorescence [78]. 8.3 Methods to Study Polymer Degradation and Deformation

On a molecular level, cover plate degradation results in chain scission in the polymer backbone, chemical reactions, e.g., oxidation of the polymer, or crosslinking. In general, the main degradation mechanisms for each cover plate material are known, although much more specific knowledge is needed regarding initiation mechanisms, rates of degradation, and synergistic effects of multiple causative factors. Many methods are available to study various aspects of polymer degradation. 
Changes in the polymer stablity as a function of temperature can be monitored using thermogravimetry (TG), DTA, DSC, and thermal

volatilization analysis (TVA) including evolved gas detection and analysis [68]. Volatile products from polymer degradation can be studied using gas chromatography (GC), gas liquid chromatography, mass spectrometry (MS), and a combination of GC and MS [68].

Chemical techniques capable of detecting chemical changes related to cover plate degradation include Fourier Transform Infrared Analysis (FTIR), Electron Spectroscopy for Chemical Analysis (ESCA), X-ray Photoelectron Spectroscopy (XPS), Auger Electron Spectroscopy (AES), Chemiluminescence (CI), and GC/MS [80]. The morphological features of surface degradation can also be studied using both optical and electron microscopy.

In cover plate materials, degradation has been exhibited as either cracking and crazing of the surface toward the sun or embrittlement of the bulk material eventually resulting in fracture. The surface degradation relates to a reduction in the molecular welght of the surface layers accompanied by yielding on a molecular level to permit cracking and crazing to occur. The cracks and crazes gradually grow from a molecular to a microscopic level and finally to a visible level. Their growth may well be enhanced by plasticization from molsture or other chemically active environment, or by fatigue, for example from thermal expansion and contraction or wind. The deformation mechanisms of polymers in general have been described in detall in Section 5.1. Polymer deformation involves molecular fracture and experimental techniques are available to study all phases of fracture. Chain scission can be followed using ESR which allows direct measurement of the number and nature of free radicals formed when bonds are broken. The reduction of molar mass due to bond breakage and the increase in concentration of end groups as measured by. IR 
can also be used to follow molecular fracture. The formation and growth of microvoids from the accumulation of chain ends and the coalescence of these voids into crazes and microcracks can be followed using small-angle $x$-ray scattering [33].

The concepts of fracture mechanics provide a sound basis on which to describe polymer fracture, however, little has been done in this area on polymers used in cover plates. In some areas, such as slow crack growth in glassy polymers, e.g. PMMA, there is quite a bit of information, while in other areas, such as environmental crack growth and fatigue life, there is little. Ductile failure is the most difficult to characterize, and most cover plate materials, other than PMMA, are ductile. Information is scarce in the study of the growth of flaws or cracks in the polymers used as cover materials. Failure of these semicrystalline materials is complex due to the multiple mechanisms of failure. It is complicated by yielding and reformation of crystals after an initial deformation. Study of the growth of cracks and flaws in cover plate materials needs more attention.

\section{Summary}

The mechanical properties of cover plate polymeric materials do not remain constant during exposure on a solar collector, rather they decline as the polymer ages. The mechanical properties are a measure of the deformation resistance of the polymer under an applied force. Polymer deformation is a complex phenomenon which is influenced by many factors including type of applied stress, temperature, characteristics of the polymer, and uniformity of properties within the polymer. The decrease in cover plate mechanical properties is a result of polymer degradation which occurs at a molecular level. Mechanical property tests are a measure of the bulk material, and appreciable degradation must occur prior to measurable change in test results. Since the decline in mechanical properties results from polymer degradation, more direct measurement of 
polymer material properties at the microstructural level would provide an indication of whether the material is changing and whether subsequent changes in mechanical properties might be expected. Monitoring microstructural properties of cover plate materials from the new material through various stages of degradation would provide degradation rate data which would aid in the prediction of service life of polymer cover plates. Unfortunately, the state of the art of structure-property knowledge for polymers in general is not sufficiently well developed to permit this at this time. However, a number of techniques are available to study cover plate materials at the molecular level to begin to build the body of knowledge necessary for accurate service life prediction. Application of modern instrumentation to study microstructure, chemical degradation, and polymer deformation and failure mechanisms will aid in developing more exact relationships between the microstructure of cover plate materials and their mechanical properties.

This study was supported by the Office of Solar Heat Technologies of the U.S. Department of Energy.

10. References

[1] R.B. Seymour and C.E. Carraher, Jr., Structure-Property Relationships in Polymers. New York: Plenum Press; 1984.

[2] S. Herzenberg, R. Silberglitt, and C. LaPorta, Materials Research Needs to Improve the Performance and Durability of Solar Heating and Cooling Systems, report prepared for the U.S. Department of Energy under contract No. DE-ACO1-80-ER30008, March 1981.

[3] W.C. Carroll and P. Schissel, Polymers in Solar Technologies: An R\&D Strategy, SERI Report TR-334-601, July 1980.

[4] R.W. Lentz, Organic Chemistry of Synthetic High Polymers. New York:Interscience Publishers; 1967. 
[5] J.D. Hoffman, G.T. Davis, J.I. Lauritzen, Jr., The Rate of Crystallization of Linear Polymers with Chain Folding, Chapter 7 in Treatise on Solid State Chemistry, Vol. 3. N.B. Hannay, ed., New York:Plenum Press; 1976. 497-614.

[6] L.E. Nellsen, Polymer Rheology. New York:Marcel Dekker; 1977.

[7] L.E. Nielsen, Mechanical Properties of Polymers and Composites, Vol. 1. New York:Marcel Dekker; 1974.

[8] F.K. Khoury and E. Passaglia, The Morphology of Crystalline Synthetic Polymers, Chapter 6 in Treatise on Solid State Chemistry, Vol. 3, N.B. Hannay, ed. New York:Plenum Press; 1976.

[9] R.F. Boyer, J. Appl. Phys. 25, 825 (1954).

[10] O.H. Wyatt and D. Dew-Hughes, Metals, Ceramics and Polymers, New York: Cambridge University Press; 1974.

[11] J.E. Dohany, L.E. Robb, in Enclyclopedia of Chemical Technology. 3rd Edition, Vol. 11. New York:John Wiley and Sons; 1980.

[12] L.M. Schlanger, E.R. Baumgaertner, and W.A. Miller, in Modern Plastics Encyclopedia. New York: McGraw-Hill, Inc.; 1983-1984.

[13] D.E. Brasure, in Encyclopedia of Chemical Technology 3rd Edition, Vol. 11. New York: John Wiley and Sons; 1980.

[14] Tedlar PVF Film Technical Bulletin TD-1A. Wilmington, DE:DuPont Company; 1982.

[15] L.F. Skoda and L.W. Masters, Solar Energy Systems--Survey of Materials Performance. Nat. Bur. Stand. (U.S.) NBSIR 77-1314, 1977.

[16] S.V. Gangal, in Encyclopedia of Chemical Technology. 3rd Edition, Vol. 11. New York:John Wiley and Sons; 1980.

[17] L.S. Luskin, in Modern Plastics Encyclopedia. New York:McGraw-Hill, Inc.; 1983-1984.

[18] J.W. Altman, in Modern Plastics Encyclopedia. New York:McGraw-Hill, Inc.; 1984-1985.

[19] A. Davis and D. Sims, Weathering of Polymers. New York:Applied Science Pub.; 1983.

[20] D.B. Jaquiss, W.F. Borman, and R.W. Campbell, in Encyclopedia of Chemical Technology. 3rd Edition, Vol. 18, New York:John Wiley and Sons; 1982.

[21] C. Nitschke, in Modern Plastics Encyclopedia. New York:McGraw-Hill, Inc.; 1984-1985.

[22] Encyclopedia of Polymer Science and Technology. Vol. 10. New York:John Wiley and Sons; 1969.

[23] R.O. Carhart, G.P. Diehl, and J.A. Avery, in Modern Plastics Encyclopedia. New York:Mc-Graw Hill, Inc.; 1983-1984. 
[24] S.L. Page, in Modern Plastics Encycloped1a. New York:McGraw-Hill, Inc.; 1984-1985.

[25] L.E. Nielsen, Mechanical Properties of Polymers and Composites, Vol. 2. New York:Marcel Dekker, Inc.; 1974.

[26] I.M. Ward, Mechanical Properties of Solid Polymers, and Edition. New York:John W1ley and Sons; 1983.

[27] R.W. Hertzberg, Deformation and Fracture Mechanics of Engineering Materials. 2nd Edition. New York:John Wiley and Sons; 1983.

[28] G.E. Dieter, Mechanical Metallurgy, 2nd Edition. New York:McGraw-Hill, Inc.; 1976.

[29] D.W. Van Krevelen and P.J. Hoftyzer, Properties of Polymers, 2nd Edition. New York:Elsevier Publishing Company; 1976.

[30] Deformation and Fracture of High Polymers. H.H. Kausch, J.A. Hassell, and R.I. Jaffee, eds. New York:Plenum Press; 1973.

[31] E.H. Andrews, Fracture in Polymers. New York:American Elsevier Publishing Company, Inc.; 1968.

[32] Fracture Processes in Polymeric Solids. B. Rosen, ed. New York: John Wiley and Sons; 1964.

[33] A.J. Kinloch and R.J. Young, Fracture Behavior of Polymers. New York:Applied Science Publishers; 1983.

[34] V.S. Kuksenko and V.P. Tamuzs, Fracture Micromechanics of Polymer Mater1als. Boston:Martinus Nijhoff Publishers; 1981.

[35] R.W. Hertzberg and J.A. Manson, Fatigue in Engineering Plastics. New York:Academic Press; 1980.

[36] Toughness and Brittleness of Plastics. R. L. Deanin and A.M. Crugnola, eds. Washington, DC:American Chemical Society; 1976.

[37] Jour. of Appl. Polym. Sci. Appl. Polymer Symposium No. 17, Mechanical Performance and Design in Polymers. O. Delatycki, ed. New York: Interscience Publishers; 1971.

[38] G.M. Bartenev and V.V. Lavrentev, Friction and Wear of Polymers. New York:Elsevier Scientific Publishing Company; 1981.

[39] V.A. Bely, A.I. Sviridenok, M.I. Petrokovets, and V.G. Savkin, Friction and Wear in Polymer-Based Materials. New York:Pergamon Press; 1982.

[40] J.G. Williams, Fracture Mechanics of Polymers. New York: John Wiley and Sons; 1984.

[41] H.V. Benig, Structure and Properties of Polymers. New York:John Wiley and Sons; 1973. 
[42] H.W. Hayden, W.G. Moffatt, and J. Wulff, The Structure and Properties of Materials, Vol. III, Mechanical Behavior. New York: John Wiley and Sons; 1965.

[43] F.M. Gavan, Tesitng of Polymers, Vol. 3, J.V. Schmitz and W.E. Brown, eds. New York:Interscience; 1967.

[44] R.S. Yamasaki and A. Blaga, Materiaux et Constructions, 10, (58), 197-203 (1977).

[45] J.R. Martin, J.F. Johnson, and A.R. Cooper, J. Macromol. Sci.-Revs. Macromol. Chem. C8 (1), 57-199 (1972).

[46] R.W. Nunes, J.R. Martin, and J.F. Johnson, Polymer Engineering and Science, 22, (4), 205-228 (1982).

[47] R.J. Gardner and J.R. Martin, J. Appl. Polym. Sci. Part A-2, 10, 571 (1972).

[48] H.B. Lee and D.T. Turner, Polymer Eng. Sci., 19, 95 (1979).

[49] A.F. Margolies, S.P.E.J., 27, 44 (1971).

[50] W.G. Perkins, N.J. Capiati, and R.S. Porter, Polym. Eng. Sci., 16, 200 (1976).

[51] S. Matsuoka and T.T. Wang, Coat, Plast. Prep. Pap. Meet, Am. Chem. Soc. Div. Org. Coat Plast. Chem. 36, 155 (1976).

[52] G. Pitman and I.M. Ward, J. Mater. Sci. 15, 635 (1980).

[53] S.L. Kim, M.D. Skibo, J.A. Manson, and R.W. Hertzberg, Polym. Eng. Sci. 17, 194 (1977).

[54] J. Michel, J.A. Manson, and R.W. Hertzberg, Polymer, 25, 1657 (1984).

[55] R.W. Hertzberg, Closed Loop, $\underline{3},(6),(1973)$.

[56] F. Bueche, J. Appl. Phys. 26, 738 (1955).

[57] J.N. Herman and J.A. Biesenberger, Polymer Eng. and Sci. 341 (1966).

[58] K.K. Devries, S. Murthy, and M. Igarashi, Environmental Stress Damage in Oriented Semicrystalline Polymers, presented at ASME Meeting November, 1984.

[59] E. Gaube and H.H. Kausch, Kunststoffe 63, 391 (1973).

[60] U.S. Gedde, S. Eklund, and J.F. Jansson, Polymer Bulletin 9, 90-97 (1983).

[61] G.P. Marshall, L.E. Culver, and J.G. Williams, Plastics and Polymers 38, 95 (1970).

[62] J.G. Williams and G.P. Marshall, Proc. R. Soc. London A342, 55 (1975). 
[63] Thermoplastics: Effects of Processing. R.M. Ogorkiewicz, ed. Cleveland: CRC Press; 1969.

[64] L.J. Broutman and F.J. McGarry, J. Appl. Polym. Sci. 9, 609 (1965).

[65] J.W. Curtis, J. Phys. D., Appl. Phys. 3, 1413 (1970).

[66] E.J. Clark and W.E. Roberts, Weathering Performance of Cover Materials for Flat Plate Solar Collectors. Nat. Bur. Stand (U.S.) Tech. Note 1170, 1982.

[67] F. Rodriguez, Principles of Polymer Systems. New York:McGraw-Hill Book Company; 1970.

[68] T. Kelen, Polymer Degradation. New York:Van Nostrad Reinhold; 1983.

[69] A. Blaga and R.S. Yamasaki, J. Mat. Sci. 11, 1513 (1976).

[70] A. Blaga, Materiaux et Constructions, 17, (98), 97 (1984).

[71] D. Waksman, W.C. Thomas, and E.R. Streed, NBS Solar Colelctor Durability/Reliability Test Program: Final Report. Nat. Bur. Stand. (U.S.) Tech. Note 1196, 1984.

[72] A. Blaga and R.S. Yamasaki, J. Mat. Sci. 8, 1331 (1973).

[73] R.K. Jain, B.K. Saxena, G.D. Bansal, and K.K. Asthana, Durability of Building Materials, 2, 27 (1983).

[74] R.S. Yamasaki, Composites Technology Review 4, (4), 125 (1982).

[75] T. Fukishima, Deterioration Process of Polymer Materials and Its Correlation with Depths from Surface, Proc. of 2nd Int. Conf. on the Durability of Building Materials and Components, September 14-16, 1981, Gaithersburg, MD, p. 367-377.

[76] W.W. Wendlandt, Thermal Methods of Analysis. 2nd ed. New York: John Wiley and Sons; (1974).

[77] Characterization of Polymers, N.B. Bikales, ed. New York:Wiley-Interscience; 1971.

[78] E.A. Collins, J. Bares, and F.W. Billmeyer, Jr., Experiments in Polymer Science. New York:Wiley-Interscience; 1973.

[79] Macromolecules, An Introduction to Polymer Science. F.A. Bovey and F.H. Winslow, eds. New York:Academic Press; 1979.

[80] V.D. McGinniss, F.A. Sliemers, D.K. Landstrom, and S.G. Talbert, Compendium of Information on Identification and Testing of Materials for Plastic Solar Thermal Collectors, DOE/CS/30171-1 report to Department of Energy, 1980. 
4. TITLE AND SUBTITLE

Molecular and Microstructural Factors Affecting Mechanical Properties of Polymeric Cover Plate Materials

5. AUTHOR(S)

Elizabeth J. Clark

6. PERFORMING ORGANIZATION (If joint or other thon NBS, see instructions) 7. Contract/Grant No.

NATIONAL BUREAU OF STANDARDS DEPARTMENT OF COMMERCE 8. Type of Report \& Period Covered

WASHINGTON, D.C. 20234

9. SPONSORING ORGANIZATION NAME AND COMPLETE ADDRESS (Street. City. State, ZIP)

Department of Energy

Washington, DC 20585

10. SUPPLEMENTARY NOTES

Document describes a computer program: SF-185, FIPS Software Summary, is attached.

11. ABSTRACT (A 200-word or less factual summory of most significant information. If document includes a significant bibliography or literature survey, mention it here)

This paper reviews the dependence of mechanical properties of polymers on various microstructural factors. The microstructural and molecular factors considered are: molecular weight, crystallinity, crosslinking, branching, copolymerization, plasticization, orientation, and residual stresses. The types of mechanical properties considered are: direct loading, fatigue, creep, wear and abrasion, and environmental stress cracking. The effects of polymer deformation and fraction at the molecular level are discussed. Cracking, crazing, and shear yielding are described. Polymeric cover plate materials are discussed and their degradation reviewed. Methods to measure microlevel changes in polymers are identified.

12. KEY WORDS (Six to twelve entries; alphabetical order; capitalize only proper names; and separate key words by semicolons) degradation; polymers; mechanical properties; microstructure; service life

\section{AVAILABILITY}

[X] Unlimited

$\square$ For Official Distribution. Do Not Release to NTIS

$\square$ Order From Superintendent of Documents, U.S. Government Printing Office, Washington, D.C. 20402.

XX] Order From National Technical Information Service (NTIS), Springfield, VA. 22161
14. NO. OF

PRINTED PAGES

67

15. Price 


